\title{
OBSERVING HURRICANE HARVEY'S EYEWALL AT LANDFALL
}

\author{
Pedro L. Fernández-Cabán, A. Addison Alford, Martin J. Bell, Michael I. Biggerstaff, \\ Gordon D. Carrie, Brian Hirth, Karen Kosiba, Brian M. Phillips, John L. Schroeder, \\ Sean M. Waugh, Eric Williford, Joshua Wurman, and Forrest J. Masters
}

\begin{abstract}
Wind velocity and radar data collected in Hurricane Harvey's eyewall at landfall offer an unprecedented glimpse into the structure of surface winds in a major hurricane.
\end{abstract}

$\mathrm{T}$ he landfall of Harvey, the first of six major Atlantic basin hurricanes of 2017, on the Texas coast ended a record-breaking quiet period for U.S. major hurricanes dating back to Hurricane Wilma (2005). Harvey was also the first category 4 hurricane to make landfall on the Texas coast since Hurricane Carla (1961) (Ho and Miller 1982; Landsea and Franklin 2013). High oceanic heat content and

AfFiliations: Fernández-CABÁn AND PHILlips-University of Maryland, College Park, College Park, Maryland; ALFORD, BiggerstafF, AND CARRIE-School of Meteorology, University of Oklahoma, Norman, Oklahoma; BeLL-WeatherFlow, Inc., Fort Collins, Colorado; HIRTH AND SCHROEDER - National Wind Institute, Texas Tech University, Lubbock, Texas; KosIBA AND WURMAN-Center for Severe Weather Research, Boulder, Colorado; WAUGH-NOAA/National Severe Storms Laboratory, Norman, Oklahoma; WILLIFORD-Weather Predict, Inc., Raleigh, North Carolina; MASTERS-University of Florida, Gainesville, Florida CORRESPONDING AUTHOR: Forrest J. Masters, masters@ce.ufl.edu

The abstract for this article can be found in this issue, following the table of contents.

DOI:10.1175/BAMS-D-17-0237.I

In final form 9 November 2018

(C2019 American Meteorological Society

For information regarding reuse of this content and general copyright information, consult the AMS Copyright Policy. favorable atmospheric conditions in the western Gulf of Mexico allowed the storm to rapidly intensify into a category 4 hurricane $\left[115 \mathrm{kt}\left(1 \mathrm{kt} \approx 0.51 \mathrm{~m} \mathrm{~s}^{-1}\right)\right.$ and $938 \mathrm{mb}(1 \mathrm{mb}=1 \mathrm{hPa})]$ before it made landfall on San Jose Island on Friday, 25 August in the evening. Due to the small wind footprint of the storm, the most severe winds were primarily limited to Aransas, Calhoun, and Matagorda Counties. Heavy damage occurred east of Corpus Christi, Texas, in smaller communities such as Rockport and Fulton, Texas (Roueche et al. 2018). Harvey then drifted over Texas for five days under weak steering currents. Its nearly stationary looping motion meant that the strong rainbands east of the circulation continuously tapped a rich supply of Gulf moisture across southeastern Texas and western Louisiana. This setup led to record Texas and U.S. storm-event rainfall accumulations, with catastrophic flooding over a wide area of southeastern Texas (Blake and Zelinsky 2018).

This paper focuses on the first interval of Harvey's landfall, presenting a composite assessment of radar and weather station observations of the storm as it moved toward and passed over Aransas Bay into mainland Texas (Fig. 1). Comparison of anemometric measurements to C-band dual-Doppler data synthesis during heavy convection expose the suspected influence of weather structures aloft on the surface wind structure, questioning how well "straight-line wind" (stationary, neutral) boundary layer profiles can 
serve as targets for similitude for computational and experimental modeling of surface winds (e.g., Masters et al. 2010). Finally, the paper presents an atmospheric sounding in the inner eyewall that appears to have produced an exceptionally large precipitable water content for observed values in the continental United States and one that ultimately presaged the extreme rain that would flood Houston, Texas, in the days that followed.

OBSERVING SYSTEMS. Data were collected by members of the Digital Hurricane Consortium (DHC) (Fig. 2), which is an ad hoc group of engineers and scientists that deploys weather stations and mobile Doppler radars in hurricane landfall regions to study a diverse range of topics such as hurricane boundary layer structure (Kosiba et al. 2013; Hirth et al. 2012; Masters et al. 2010; Knupp et al. 2006; Wurman and Winslow 1998; Lorsolo et al. 2008), lightning (Pilkey et al. 2013), inner-core dynamics (Alford and Biggerstaff 2015; Alford et al. 2016), and eyewall asymmetries and mesovortices (Wingo and Knupp 2016). The program collects perishable meteorological data in the landfall region leading up to and through the landfall. In addition to supporting basic science research, these measurements are used by the operational meteorology, emergency management, and catastrophe modeling communities to monitor decaying weather conditions at landfall and to analyze the surface wind field after an event. For the members of this program, which have collected surface observations in landfalling storms since the late 1990s, Harvey was one of the most intense storms measurements were captured in to date.

A network of 14 federal and state surface observations stations also reside in the landfall region. These are supplemented by 19 local mesonet stations from WeatherFlow, the Texas Coastal Ocean Observation Network (TCOON), and Earth Networks. These stations collect a range of surface wind data, from the 15-min averages of the National Ocean Service (NOS) National Estuarine Research Reserve (NERRS) sites, for the 3-s data from the Hurricane Hardened WeatherFlow network. The appendix contains the metadata (height, sampling characteristics) for the nonfederal mesonets.

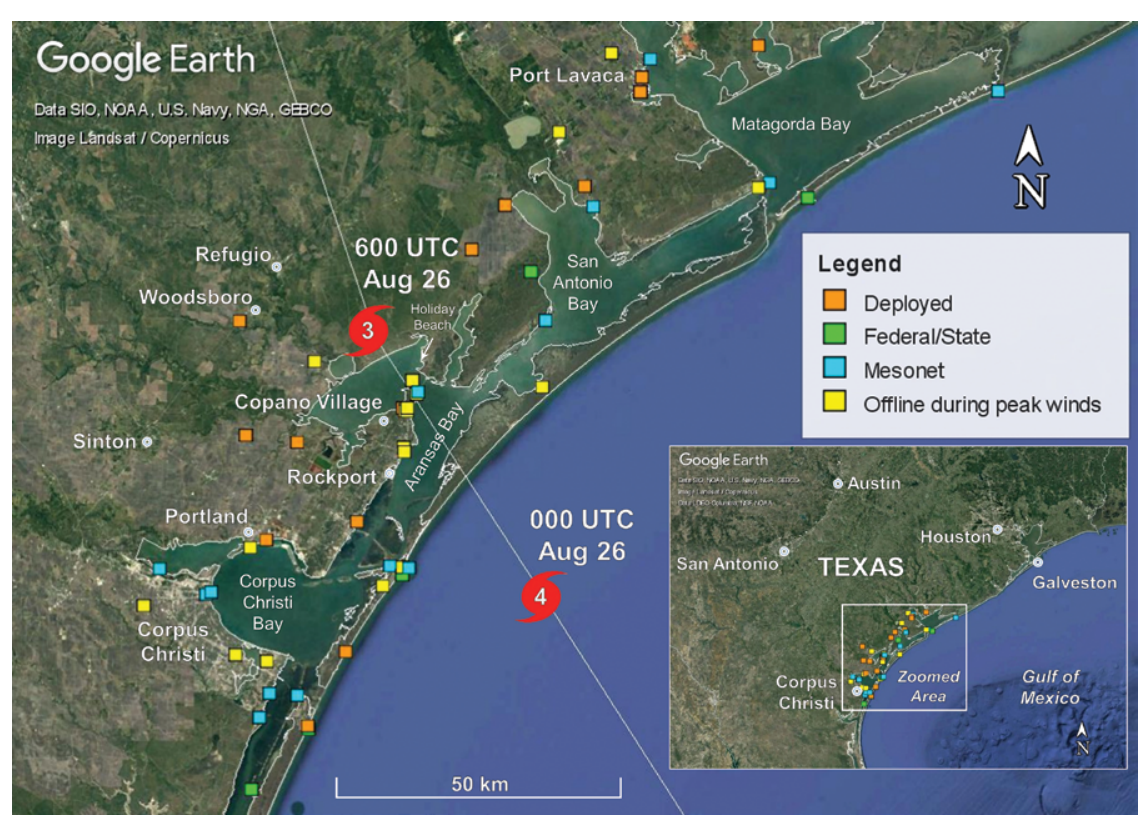

FIG. I. Map of all in situ and adaptive surface assets deployed for Hurricane Harvey. Yellow labels indicate stations that did not capture peak winds due to, for example, station failure/destruction, loss of power, loss of connectivity, or loss of data. The dataset was significantly enriched by the private mesonet assets, most notably in the swath of very high impact from Holiday Beach, through Rockport, and to Port Aransas. The more specialized adaptive and local mesonet observations proved to be collectively more reliable than the in situ state and federal networks, yielding a $74 \%$ success rate in capturing peak winds over land vs only $36 \%$ for the state and federal sites. Indeed, only 5 federal/state stations (shown in green) out of 14 were online when the peak winds occurred.
THE INTERCEPT. Planning for and conducting field experiments in tropical storms that form in the Gulf of Mexico are complicated by the storm's close proximity to the coast. Harvey, which rapidly regenerated from a tropical wave and subsequently intensified into a major hurricane less than $150 \mathrm{~km}$ from the coastline left little time for teams to travel from their home institutions to the projected landfall site.

Texas Tech University (TTU) was the first to deploy, sending a team from Lubbock, Texas, to Corpus Christi on 23 August 2017 to scout for potential sites that formed a measurement array on each side of the anticipated landfall point, while ensuring these sites provided reasonable access and sufficient elevation to 
protect from storm surge and freshwater flooding. Potential access difficulties forced the team to reposition to Mustang Island early on 24 August, where the deployment of StickNets was initiated. TTU then deployed three additional stations near the more densely populated areas of Portland, Aransas Pass, and Copano Village, Texas, followed by a move northward into rural areas near Port Lavaca, Texas, to complete a total of eight deployments on this day. The next morning on 25 August, TTU added three stations to extend the network northward and anticipate any northward drift of the landfall point. As uncertainty in the track guidance dropped during the day, the team circled back south to densify the mesonet near Fulton, which is located north of Rockport and west of Aransas Bay.

On 24 August, teams from the University of Oklahoma (OU) and the National Severe Storms Laboratory (NSSL) deployed three vehicles carrying mobile radar, anemometers, and upper-air measurement equipment, reaching the Texas coast on the morning of 25 August. The C-band Shared Mobile Atmospheric Research and Teaching (SMART) radar was then deployed near Woodsboro, Texas, along US 77 to sample the eyewall and innercore structure of the hurricane during landfall without putting the team in the direct path or at risk of flooding (Fig. 3). Radar operations started at 2002 UTC 25 August and concluded at 1430 UTC 26 August. There were two periods during which the radar was down due to loss of antenna control caused by strong gusty winds during RHI scans, namely from 2310 to 2349 UTC and from 0145 to 0312 UTC. In all, more than $16 \mathrm{~h}$ of dual-Doppler coverage with the Corpus Christi Weather Surveillance Radar-1988 Doppler (WSR-88D) were obtained during the hurricane's landfall.

As Harvey approached and made landfall late Friday evening, the NSSL Mobile Mesonet launched two radiosonde soundings near Woodsboro into the outer rainbands (1954 UTC 25 August and 0136 UTC 26 August) and performed several transects through
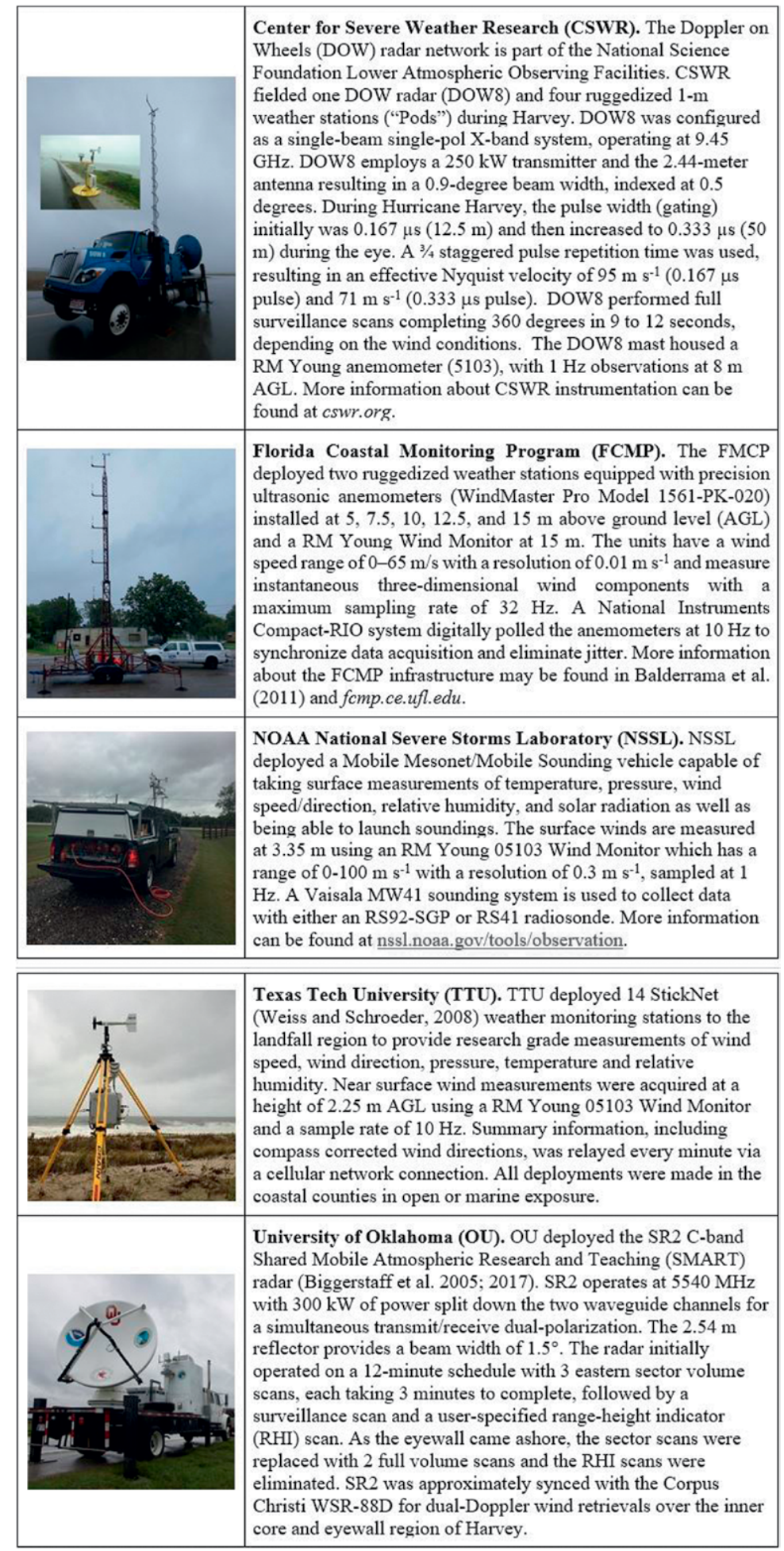

FIG. 2. Observation assets in the DHC (Balderrama et al. 20II; Weiss and Schroeder 2008; Biggerstaff et al 2005, 20I7).

Harvey's western precipitation region as conditions permitted. The eyewall convection was strongest on the western quadrant of Harvey and remained so during landfall. At approximately 0430 UTC 26 August, a brief transect was made into the outer 
edge of the western eyewall along US 188 east of Sinton, Texas. At approximately 0600 UTC 26 August, conditions permitted the redeployment of the mobile mesonet to a location within Refugio, Texas, to facilitate both direct surface observations of the eye and eyewall as it passed over and launching a sounding within the eye itself. At 0716 UTC, the third and final sounding of the deployment was launched in Refugio. The mobile mesonet collected 1-s surface observations from a period spanning roughly from 1830 UTC 25 August to 1630 UTC 26 August.

The Florida Coastal Monitoring Program (FCMP; Balderrama et al. 2011), which was led by the University of Florida and the University of Maryland, mobilized four chase vehicles equipped with two 15-m weather stations (T2, T3) late Thursday afternoon (24 August). Following the 1000 central daylight time (CDT) National Hurricane Center (NHC) forecast and with consultation with WeatherPredict Consulting, Inc., the FCMP team arrived in Port Lavaca on 25 August to initiate deployment of weather station $\mathrm{T} 2$ in suburban conditions to study the wind structure of the roughness sublayer. Forecast guidance subsequently shifted the landfall forward approximately $6 \mathrm{~h}$, forcing the team to split in two to complete the deployment. After consulting with local authorities and reviewing storm surge and

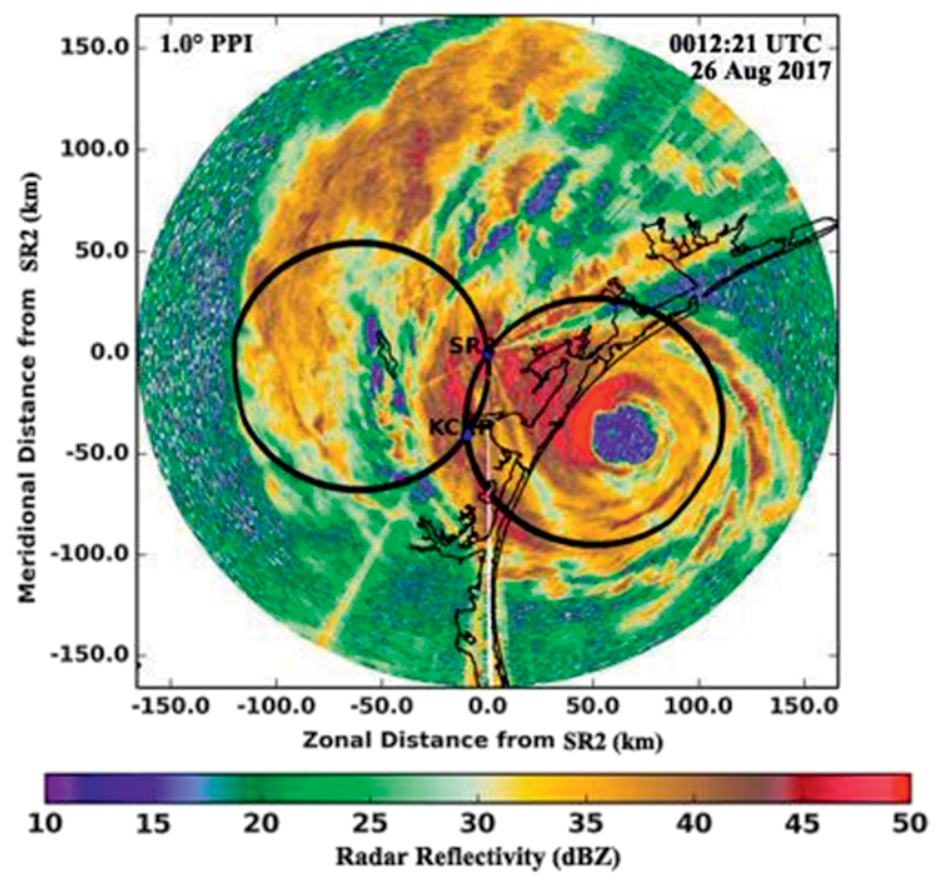

FIG. 3. Radar reflectivity at $1.0^{\circ}$ elevation angle from the SMART radar (SR2) at 0012 UTC 26 Aug 2017 showing the location of Harvey's eye relative to the dual-Doppler lobes (black circles) in which the three-dimensional flow can be retrieved. wave predictions [Advanced Circulation/Simulating Waves Nearshore (ADCIRC/SWAN)] from the Coastal Emergency Risks Assessment tool (https:// cera.coastalrisk.live), the first team deployed T3 in the parking lot of a store located in a suburban neighborhood $500 \mathrm{~m}$ from Lavaca Bay. The second FCMP team drove to Fulton where the Center of Severe Weather Research (CSWR) had recently arrived to deploy the $\mathrm{X}$-band Doppler on Wheels 8 (DOW8) radar and multiple weather stations. Coordinating with the Aransas County Airport manager, both teams deployed on site in the afternoon. The FCMP deployed T2 at the western edge of the runway, which presented nominally 500-1,500 m of open exposure (smooth, flat terrain) in the expected prevailing wind direction. The weather stations collected data continuously through landfall, capturing five levels of 3D ultrasonic wind data at the T2 and T3 sites, respectively.

CSWR advance teams scouted locations for DOW8 and pods along the coastline from Corpus Christi to Long Mott, Texas, settling on the Aransas Airport as the closest well-exposed, low-horizon site to the anticipated landfall point. CSWR deployed DOW8 and two pods on a taxiway at the airport, and two additional pods on the bridge across the inlet between Copano and Aransas Bays a few kilometers to the north. DOW8 raised a masted anemometer to a height of $8 \mathrm{~m}$ AGL. The DOW8 radar collected data from 2220 UTC 25 August to 0203 UTC 26 August and then again from inside the eye from 0356 to 0540 UTC 26 August. The DOW8 anemometer collected data from the start of the deployment at 2200 UTC 25 August until approximately 0700 UTC 26 August, and the pods collected data from the start of the deployment until they were hit by debris, which varied by pod from $\sim 0130$ to 0230 UTC 26 August.

DOPPLER RADAR ANALYSIS. As noted in the National Hurricane Center tropical cyclone report for Hurricane Harvey (Blake and Zelinsky 2018), mesovortices were observed during landfall. Dual-Doppler analysis (Fig. 4) shows several inner-core rainbands that likely developed in association with vortex Rossby waves (Abdullah 1966; Montgomery and Kallenbach 1997; Chen and Yau 2001; Corbosiero et al. 2006; Menelaou and Yau 2014; Gao and Zhu 2016) that were emanating from asymmetries in the eyewall convection, numerous rapidly 
0314 UTC | z = $0.50 \mathrm{~km}$ MSL | Harvey

(a) $Z_{H}$ and Tangential Wind Vectors $\left(\mathrm{m} \mathrm{s}^{-1}\right)$

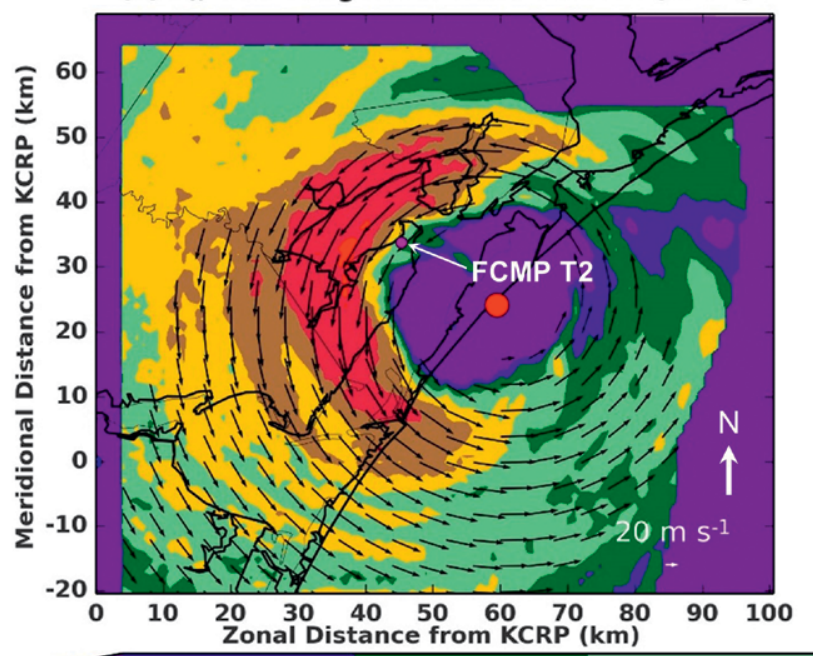

(b) $Z_{H}$ and Radial Wind Vectors $\left(\mathrm{m} \mathrm{s}^{-1}\right)$

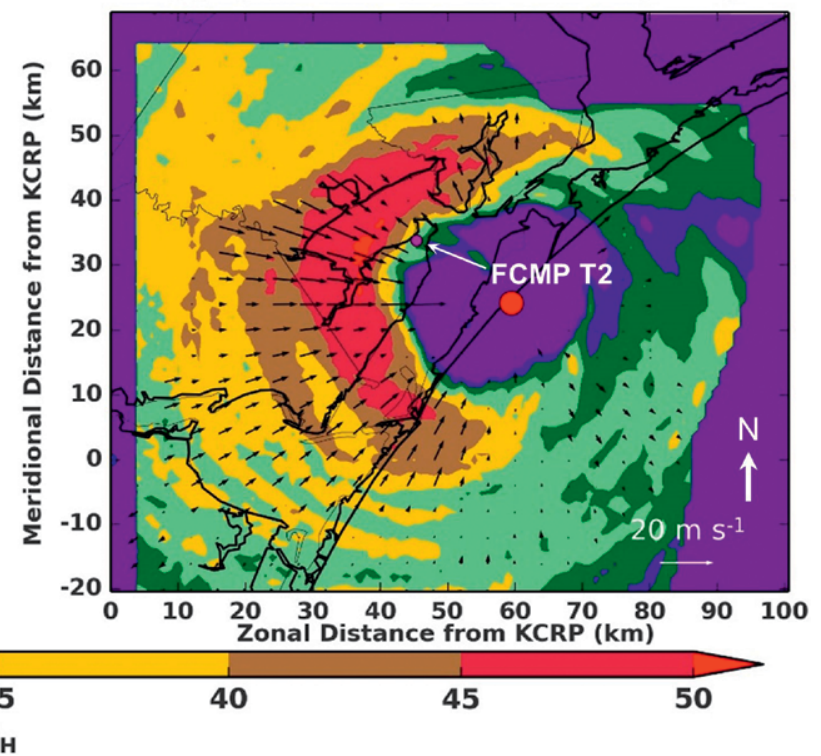

(d) KCRP Dealiased $V_{R}-031302$ UTC $-0.5^{\circ}$

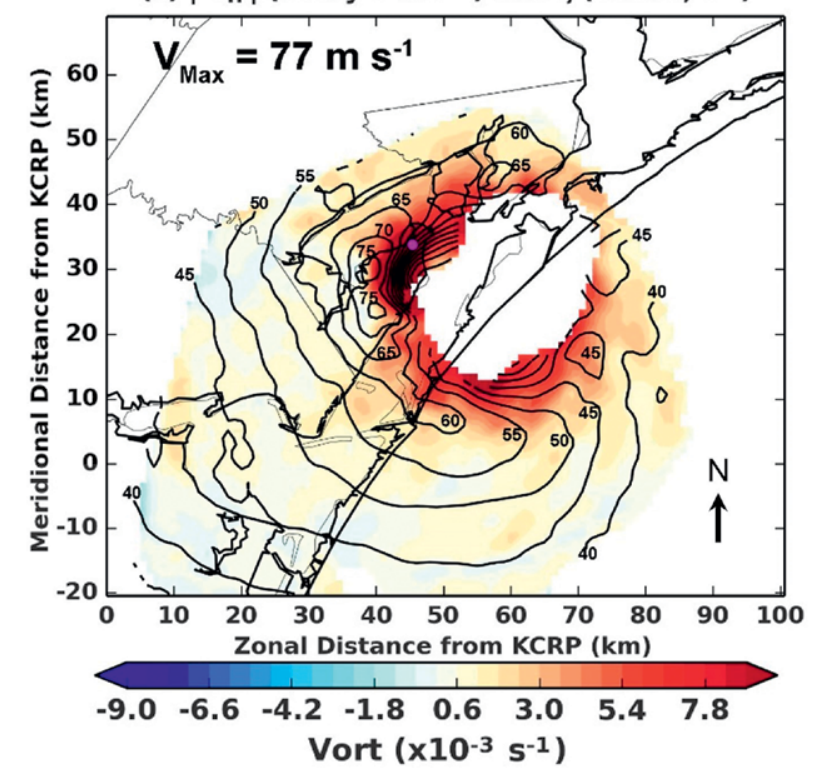

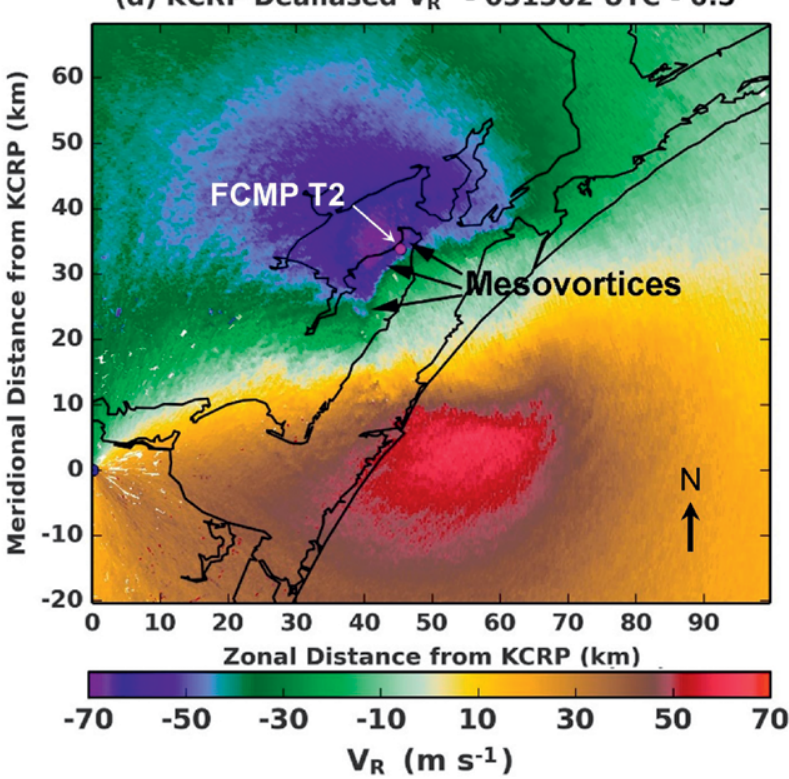

Fig. 4. Dual-Doppler analysis of the OU SR2 and KCPR WSR-88D at 0314 UTC showing (a) the tangential component of the wind overlaid on radar reflectivity, (b) the radial component of the wind overlaid on radar reflectivity, and (c) wind speed contours overlaid on vertical vorticity. (d) The 0313 UTC KCRP WSR-88D dealiased radial velocity at $0.5^{\circ}$ elevation angle. Note the different scales for the $20 \mathrm{~m} \mathrm{~s}^{-1}$ wind speed in (a) and (b). The large red dot in (a) and (b) indicates the estimated location of the center of the eye. The smaller purple dot in all panels is the location of the T2 tower deployed by the FCMP.

developing outer rainbands, the eyewall itself, and a handful of mesocyclone-scale vortices that circulated along the interior of the eyewall. These features (Figs. 4a,b) propagated azimuthally along the radial gradient in vorticity (Fig. 4c) and appeared to lead to the formation of sheared vortex Rossby waves radially outward from the eyewall. The waves in the interior of the eyewall were associated with regions of strong radial inflow and outflow (Fig. $4 \mathrm{~b}$ ), suggesting the waves redistributed momentum in the eyewall region.

The transport of high-entrophy air from the eye into the eyewall is thought to enhance local convective instability (Braun 2002; Persing and Montgomery 2003; Eastin et al. 2005). Indeed, similarly to the mesovortex observed over water in Hurricane Hugo (Black and Marks 1991; Marks et al. 2008), the mesovortex 


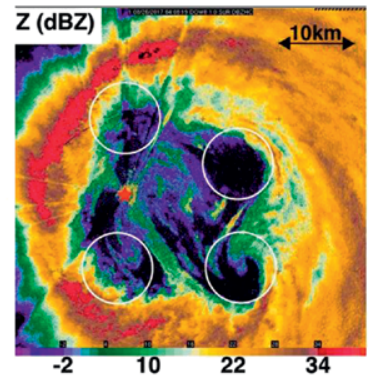

(a) Radar reflectivity of eyewall mesovortices|(white circles) at 0408:18 UTC

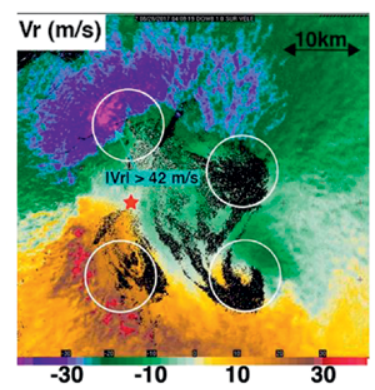

(b) Corresponding Doppler

velocity. Magenta velocity contours depict Doppler winds in excess of $42 \mathrm{~m} \mathrm{~s}^{-1}$.

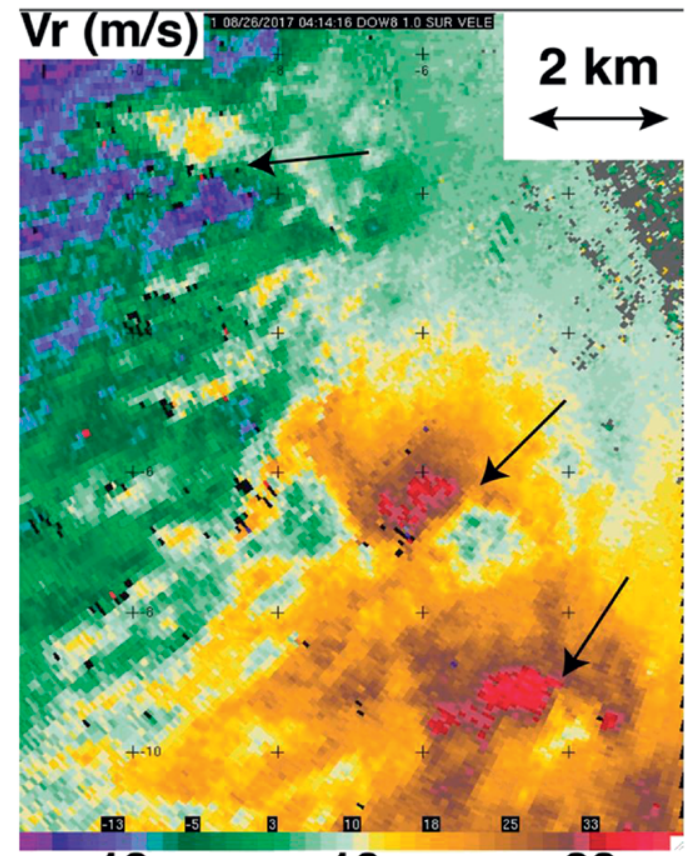

$-13$ 10

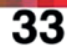

(c) Tornado-scale vortices (TSVs) observed by DOW8 at 0414:16. Arrows indicate the location of three prominent TSVs. Shown is Doppler velocity in $\mathrm{m} \mathrm{s}^{-1}$.

FIG. 5. Radar observations by the DOW8 mobile radar (Wurman and Kosiba 2018).

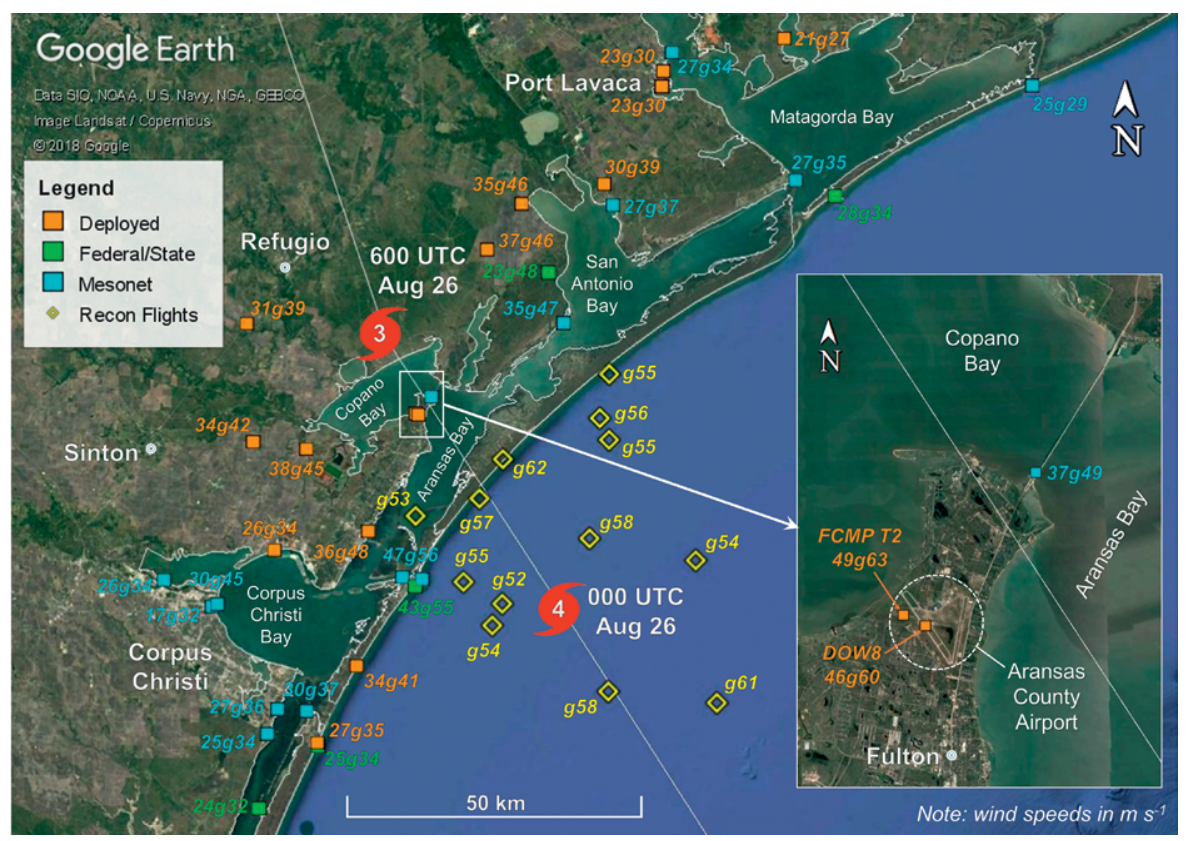

FIG. 6. Maximum sustained wind speeds and gusts $\left(\mathrm{m} \mathrm{s}^{-1}\right)$ in the storm for all fixed, portable, and mobile observation platforms that captured peak winds at some point during Harvey's landfall. The U.S. Air Force (USAF) reconnaissance flight data are the maxima observed in the eyewall during Stepped Frequency Microwave Radiometer (SFMR) transects and the lowest $150-\mathrm{m}$ averages of the eyewall dropsondes. Data in this figure represent a variety of observational techniques and averaging times that are detailed in the appendix. observed in Harvey at 0314 UTC was near the inner edge of a strong reflectivity core in the eyewall convection. However, the mesovortex in Harvey also formed near the land-ocean interface where enhanced low-level convergence from the change in surface roughness (Hirth et al. 2012) would have further enhanced low-level vorticity. It is possible that the vortex Rossby wave generated by the convective asymmetry in the eyewall of Harvey produced a vorticity perturbation that was stretched by a low-level updraft fed by the boundary layer convergence along the land-ocean interface. A similar evolution was observed during the landfall of Hurricane Hermine in 2016 (Alford and Biggerstaff 2017). In Hermine, low-level convergence along the ocean-land interface led to the development of a cyclonic eddy along the inner edge of the eyewall and a $20 \%$ increase in the wind speed. The Harvey mesovortex was also associated with a reflectivity filament that extended inward toward the center of circulation. Aberson et al. (2006) noted a similar reflectivity feature for a mesovortex found along the inner edge of the eyewall of Hurricane Isabel.

Over water, extreme gusts and strong vertical drafts have been previously documented in meso- and misovortices near hurricane eyewalls (Marks et al. 2008; Aberson et al. 2017). Mesovortices near the 
land-sea interface, such as the one observed in Harvey, were documented previously in Tropical Cyclone Oliva by Black et al. (1999). In Olivia, a mesovortex produced several 3-s gusts larger than $102 \mathrm{~m} \mathrm{~s}^{-1}$ on the interior edge of the eyewall with gust factors, namely the ratio of the short-duration peak to the mean of its record, that exceed 2.5 times the background flow. In contrast to Hurricane Harvey, comparison between radar-derived wind fields, precipitation structure, and ground-based in situ observations was not possible for that storm.

Additional mesovortices in Harvey were observed by CSWR DOW8 before and after the eyewall passed their location. Before to the passage of the eye, DOW8 conducted shallow volumes scans $\left(0.5^{\circ}, 1.0^{\circ}\right.$, $1.5^{\circ}$ elevation) with short gates $(12.5 \mathrm{~m})$ and reduced range $(12.5 \mathrm{~km})$ to capture the evolution of coherent boundary layer structures, such as hurricane boundary layer streaks and rolls (Wurman and Winslow. 1998; Morrison et al. 2005; Lorsolo et al. 2008; Kosiba et al. 2013). The DOW collected approximately $4 \mathrm{~h}$ of data in this mode before the antenna failed due to the strong winds. By 0356 UTC, once DOW8 was in the eye, the winds at the DOW8 location had subsided and scanning resumed. DOW8 conducted fast surveillance scans at $\sim 1^{\circ}$ elevation, with $50-\mathrm{m}$ gates and $50-\mathrm{km}$ range, from inside the eye of Harvey (Fig. 5). The range of the mesovortices from the $0.9^{\circ}$-beamwidth DOW varied from less than 5 to almost $20 \mathrm{~km}$. This allowed a fine temporal scale in the observation and tracking of several eyewall mesovortices (5-8 km in diameter) (Fig. 5). Additionally, tornado-scale vortices (TSVs), with diameters of approximately $1 \mathrm{~km}$, were observed in the eyewall (Fig. 5c). These TSVs were associated with some of the most intense near-surface Doppler velocities observed by the CSWR team inland and are suspected to correlate with regions of enhanced damage (Wurman and Kosiba 2018).

THE SURFACE WIND FIELD. Figure 6 presents the sustained and peak gust wind speed measurements for the adaptive and fixed observational networks. It is evident from the magnitudes shown that the highest wind speeds were confined to approximately $30 \mathrm{~km}$ on either side of the track. The highest wind speed observations in the storm were measured in the Fulton and Rockport areas, where extreme damage occurred. Figure 7 shows photographs taken approximately $300 \mathrm{~m}$ north of DOW8 and FCMP T2.

Figure 8 shows the measured wind speeds from four observations collected by the FCMP and CSWR assets located $500 \mathrm{~m}$ apart at the site. The 3-s movingaverage gust speed reached $65 \mathrm{~m} \mathrm{~s}^{-1}$ at the $15-\mathrm{m}$ elevation in open exposure conditions. The American

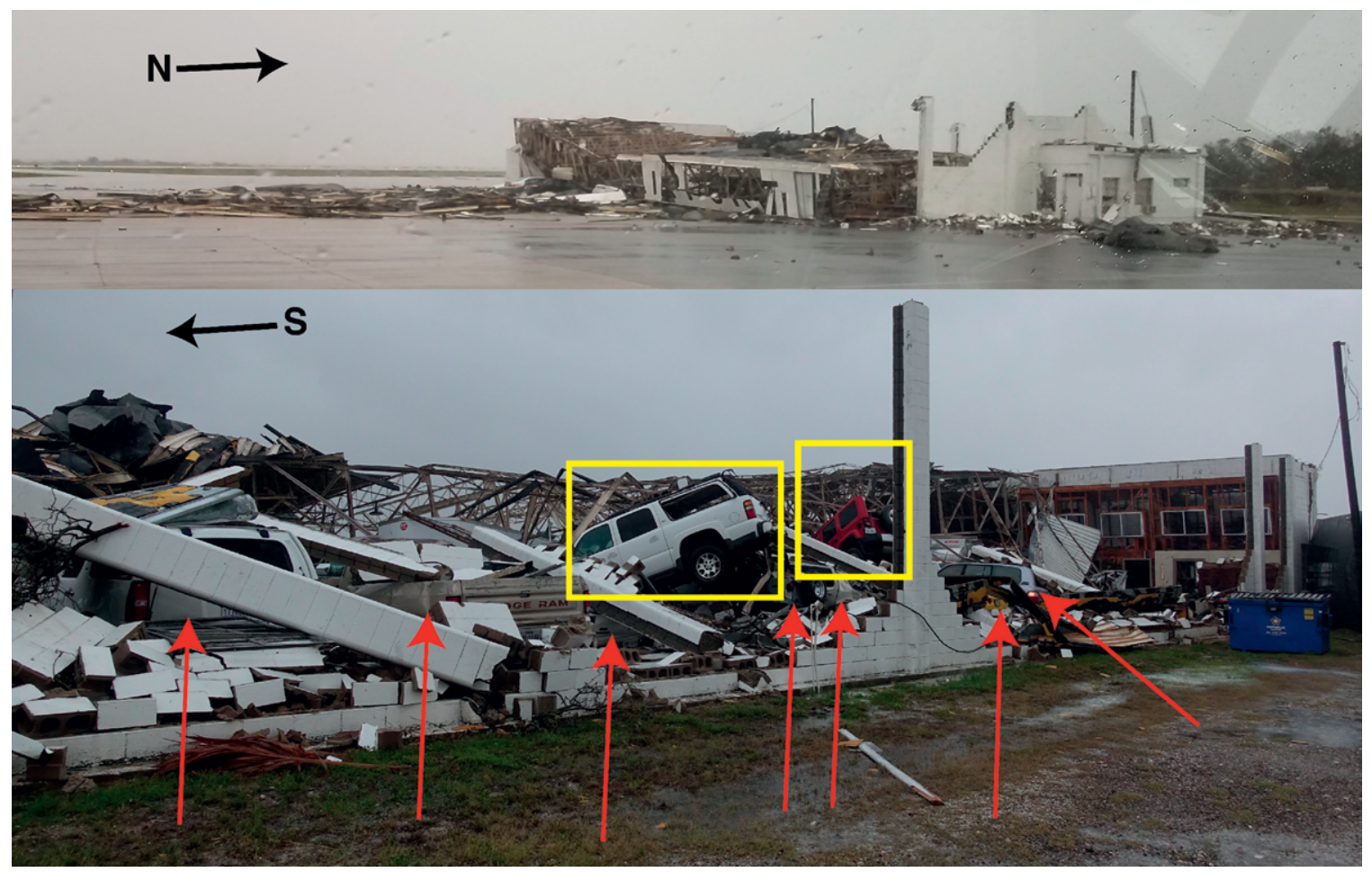

FIG. 7. Damage to buildings and cars (yellow boxes) near the DOW8 location at the Aransas County Airport (Wurman and Kosiba 2018). 


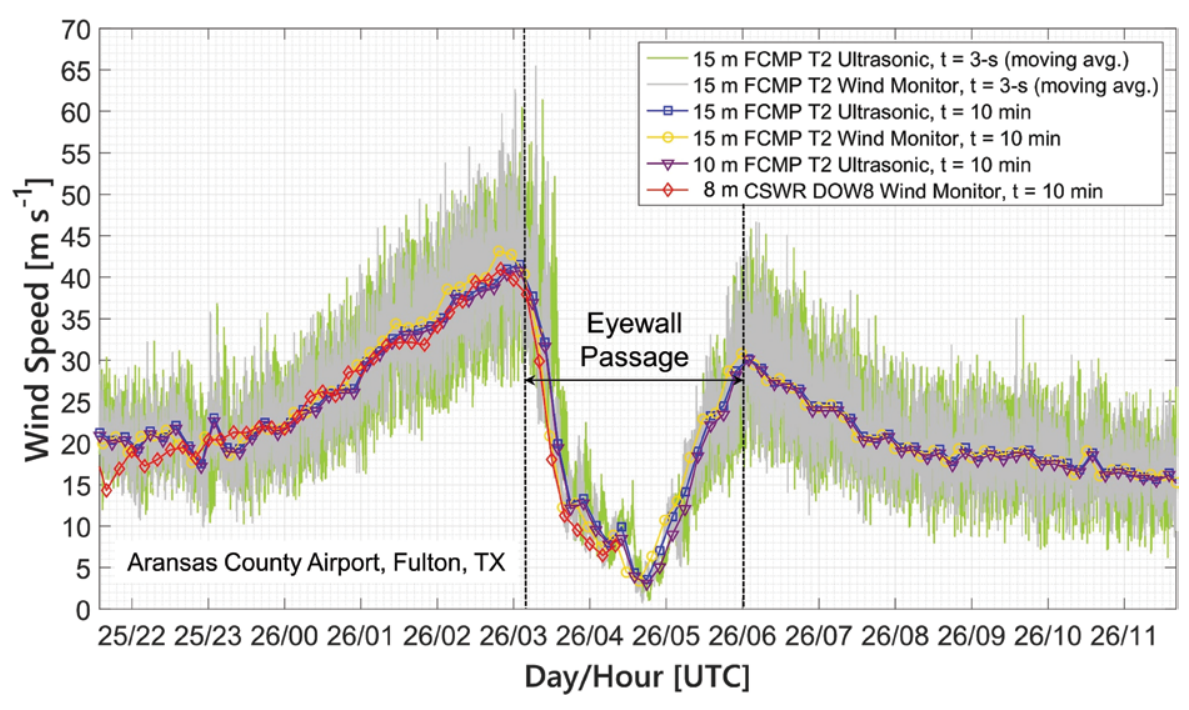

Fıg. 8. Anemometric records obtained at the Aransas County Airport in Fulton.

(a)

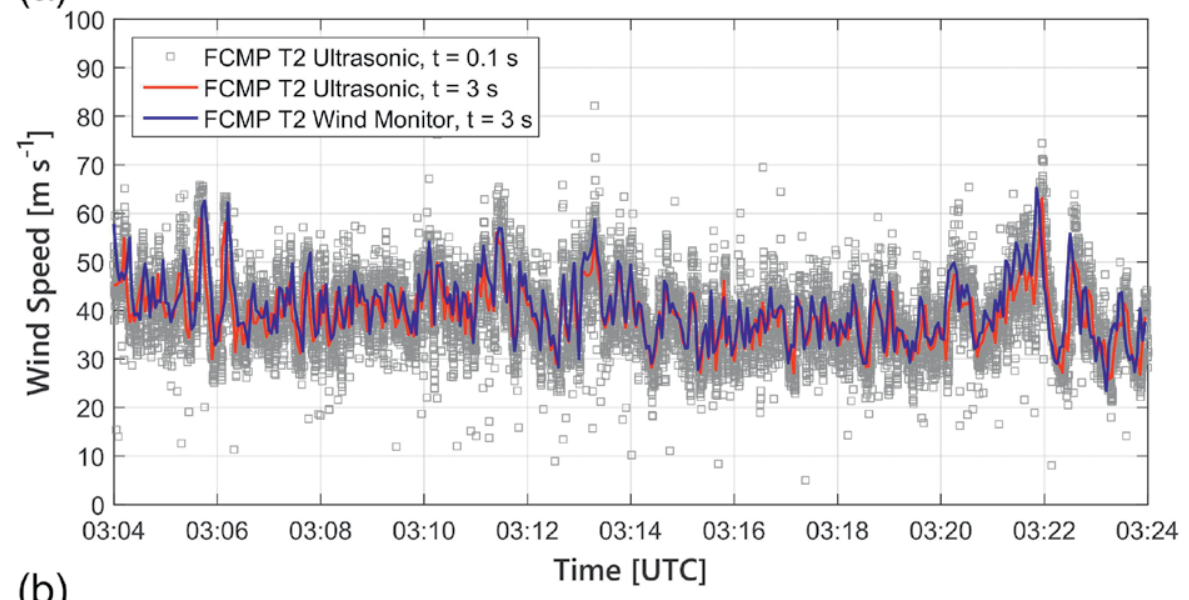

(b)

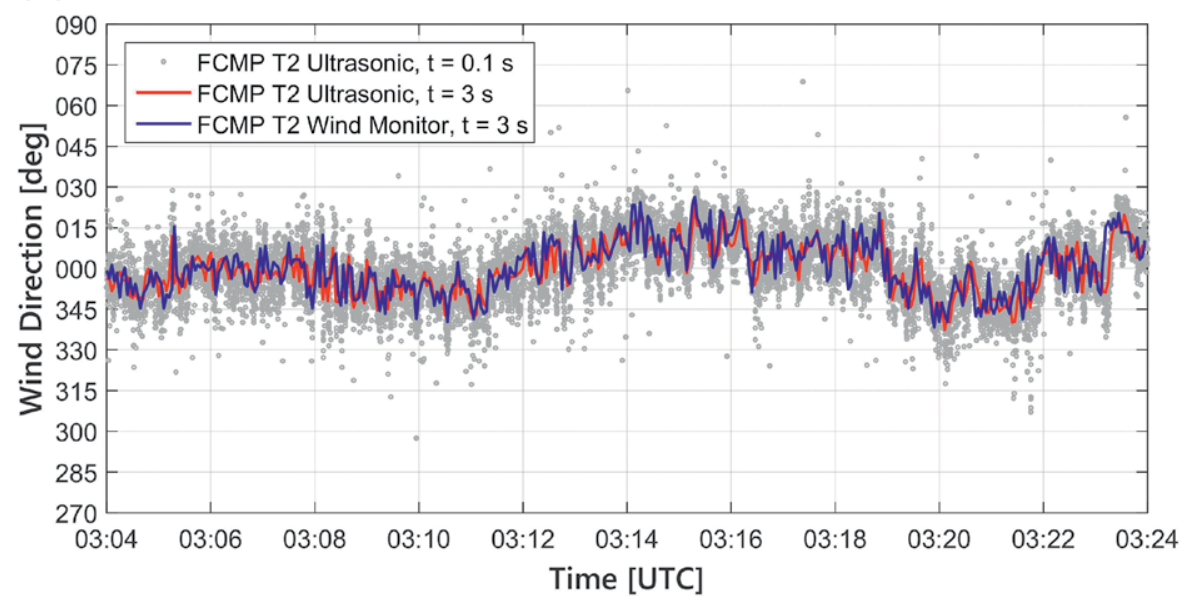

FIG. 9. The 20-min record of (a) wind speed and (b) wind direction collected by FCMP tower T2 starting at 0304 UTC. The red and blue records are 3-s segmented (block) averages, whereas the gray velocity traces correspond to instantaneous $(10 \mathrm{~Hz})$ records from the ultrasonic anemometer. The wind monitor and ultrasonic anemometer were both located 15 m AGL.
Society of Civil Engineers (ASCE) 7 (2016) bounds the design wind speed for the Texas coastal region between Corpus Christi and Houston between 63 and $67 \mathrm{~m} \mathrm{~s}^{-1}(3-\mathrm{s}$ gust at $10 \mathrm{~m}$ in open exposure terrain). This value corresponds to a $700-y r$ mean recurrence interval, or a $1 / 700$ likelihood, that these wind speeds will be exceeded in a given year. Surface-level data collected by the Digital Hurricane Consortium approached this threshold, making it one of only a few storms in the last two decades to produce winds sufficiently extreme to test modern building codes and standards.

Figure 9 shows the wind speed and direction for the 20-min interval containing the two largest gusts measured by the wind monitor and ultrasonic anemometer of T2 at $15 \mathrm{~m}$ AGL. The records, which were obtained during the same interval as Fig. 4, immediately preceded the passage of the eyewall. Around 0314 UTC (halfway through the record), the $\mathrm{OU}$ radar retrieved wind speeds of $57 \mathrm{~m} \mathrm{~s}^{-1}$ at $500 \mathrm{~m}$ over the site, which was located in a region of strong cyclonic shear that was slightly upwind of the strongest winds that exceeded $80 \mathrm{~m} \mathrm{~s}^{-1}$ at $500-\mathrm{m}$ altitude. The cyclonic shear was evident both in the tangential winds along the inner edge of the eyewall (Fig. 4a) and in azimuthal gradients in the radial wind (Fig. 4b). A reflectivity filament attached to the strongest shear zone and extending into the eye of Harvey was also evident near T2. Within $2 \mathrm{~min}$, the 
asymmetries were associated with mesovortices (Fig. 4d), one of which passed close to T2.

Wurman and Kosiba (2018) link 500-750-s periodicity in anemometer observation to the passage of mesovortices. Similarly, three pronounced $\left(>30 \mathrm{~m} \mathrm{~s}^{-1}\right)$ variations in the $\mathrm{T} 2$ gust records occur beginning at around 0305, 0311, and 0321 UTC (Fig. 9a). While these variations cannot be explicitly linked to the presence of the mesovortex, it does raise a question about how the phenomenology of kilometer-scale storm features informs our understanding of extreme winds. For example, the dominant assumption in the design of buildings and other structures is that velocity records
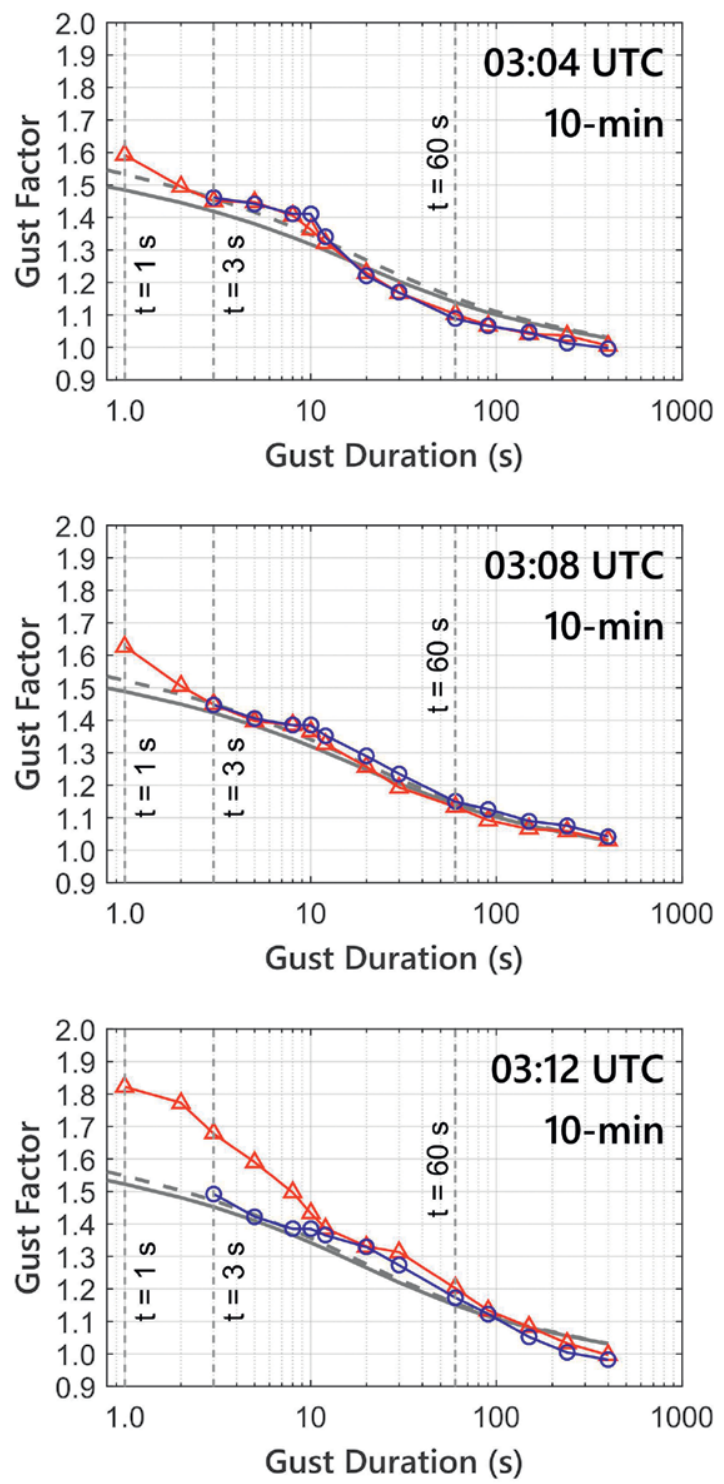

can be considered as weakly stationary, and thus describable by an established power spectral density model (e.g., von Kármán 1948). These features, which last up to $2 \mathrm{~min}$ and span several kilometers in scale, are not expected to be captured by spectral models calibrated to mechanical turbulence generated by terrain.

Furthermore, the effect of localized nonstationarity can be seen in the comparison of the observed gust factors (GF) to their theoretical equivalents in Fig. 10. The plot shows six GF plots calculated from a 10-min window that starts at 0304 UTC, with each plot successively shifting by $2 \mathrm{~min}$. Data were linearly detrended to remove the nonstationary trend in the mean, and gust
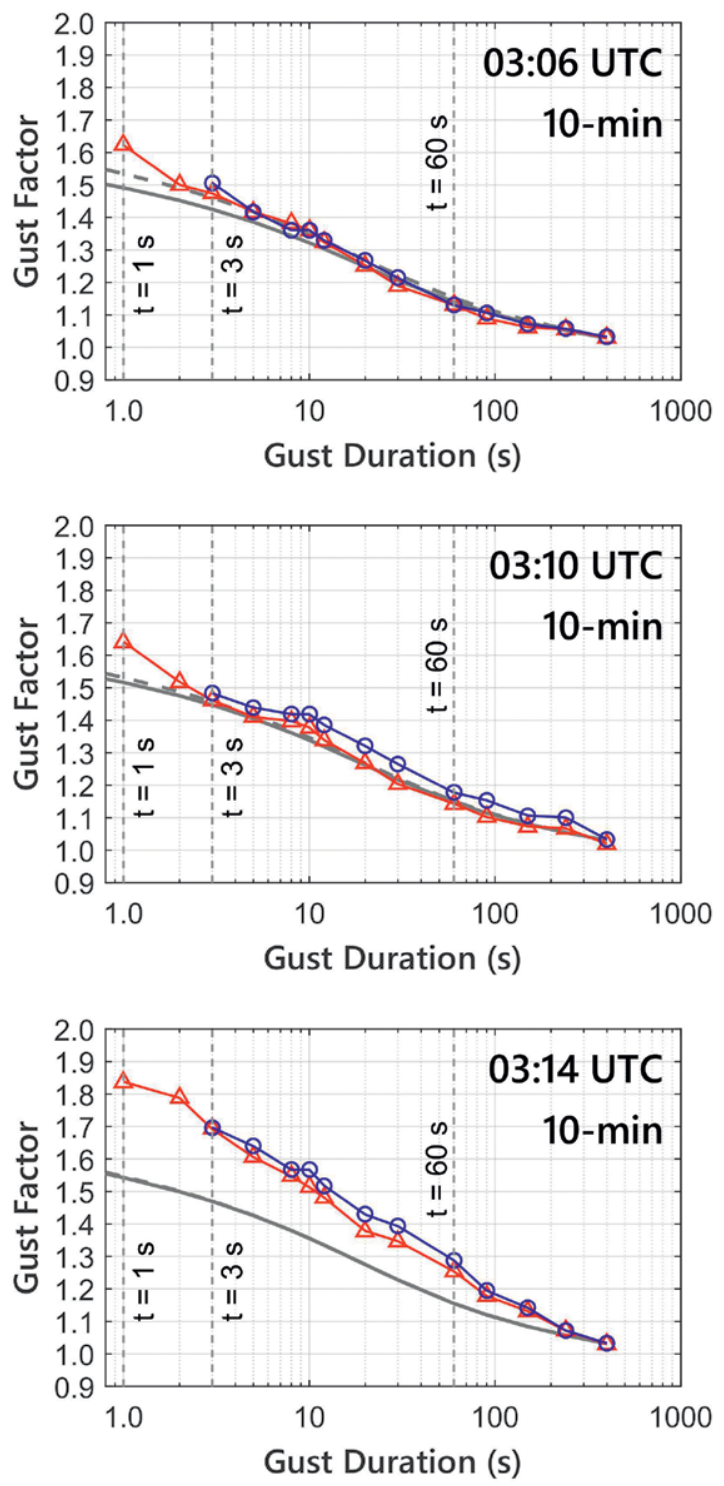

— Theoretical for WM - - - Theoretical for Ultrasonic $\_$FCMP T2 Ultrasonic —— FCMP T2 Wind Monitor

FIG. 10. Gust factor analysis of 10-min wind records obtained from FCMP tower T2 from (top left) 0304 to (bottom right) 0314 UTC at 2-min intervals. The theoretical GF models were generated from the roughness length $\mathrm{z}_{0}$ calculated from the longitudinal turbulence intensity. 
averages were obtained from a moving average if at least $80 \%$ of the data were available. This second step was necessary because the Gill WindMasterPro ultrasonic has a published rating of $0-65 \mathrm{~m} \mathrm{~s}^{-1}(0-145 \mathrm{mph})$; however, instantaneous $(0.1 \mathrm{~s})$ velocities reached $78-86 \mathrm{~m} \mathrm{~s}^{-1}$ (174-191 mph). Gill subsequently confirmed the validity of the measurements after reviewing our data, notwithstanding interference from the probe head, and estimated that the measurement error would be $6 \%-9 \%$ in the peak wind measurements (R. McKay 2018, personal communication). With the exception of the 0312 UTC plot, the ultrasonic and wind monitor records match reasonably well, with some variation being attributed to missing data in the ultrasonic record.

The effect of the third pronounced variation (onset at 0321 UTC) in the surface flow is clearly seen in the bottom-right plot. The longitudinal turbulence intensity for the six plots range from $16 \%$ to $19 \%$, which aligns with open exposure. However, the 3-s gust factor approaches 1.7, whereas the model predicts $1.46-1.49$ for a roughness length $z_{0}=[0.05,0.08] \mathrm{m}$, and Wurman and Kosiba (2018) report 3-s gust factors at the DOW of 1.51. Inspection of higher-order statistical moments of the wind velocity time histories found non-Gaussian behavior, which is not expected to occur in smooth open terrain. The skewness and kurtosis values of the detrended record are 0.57 and 3.97, respectively. This finding may point to the need to incorporate non-Gaussian models (Kwon and Kareem 2009; Fernández-Cabán and Masters 2017) as a first approximation to capture the effects of

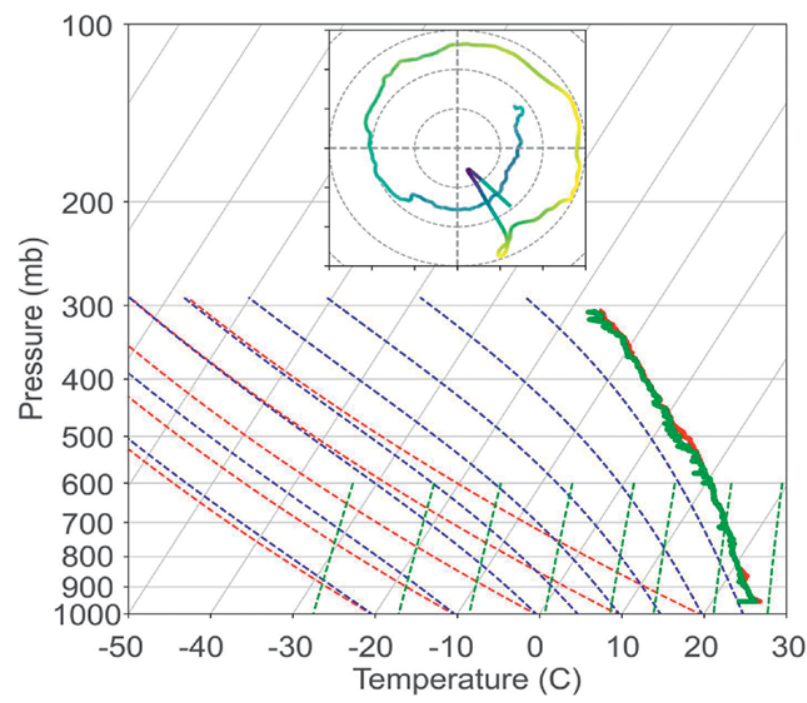

FIG. II. Sounding in the inner eyewall from a launch near Refugio at 0716 UTC 26 Aug 2017 obtained by the NSSL and $O U$ teams. The circular hodograph represents a $0-3-\mathrm{km}$ storm-relative helicity value of $-1,847 \mathrm{~m}^{2} \mathrm{~s}^{-2}$, and the total profile contains $8.3 \mathrm{~cm}$ of precipitable water. storm features not expected to occur in straight-line winds. Ultimately, it underscores the need to shift from engineering methods (which apply principles of boundary layer meteorology and signal processing) to physics-based numerical weather prediction tools that use computational fluid dynamics models (e.g., largeeddy simulation) to predict/hindcast surface flows.

PRECIPITABLE WATER CONTENT. A unique aspect of the deployment to Hurricane Harvey was the ability to obtain a vertical sounding from inside the closed eye structure. Even though it is not the first sounding of this kind (Franklin et al. 1988), surfacebased soundings in hurricanes, specifically in the eye or eyewall of hurricanes, are a rare occurrence. McCaul (1991) has indeed stated that rawinsonde observation data inside the core regions of hurricanes are lacking but would be very useful in characterizing the environment of landfalling systems. Given the spacing of the RAOB network and the difficulty of launching soundings in hurricane conditions, McCaul further argued that mobile in situ crews would be a potential source for these soundings. Understanding the inner-core environment of landfalling hurricanes is paramount to issues such as tornadoes during landfall of tropical cyclones (Curtis 2004; Baker et al. 2009). While dropsondes are regularly utilized by NOAA to facilitate measurements of the vertical profile of hurricanes and their environment, such observations are collected mostly over the open ocean and never within the eyewall of a landfalling hurricane. Moreover, the slow ascent rate (nominally $5 \mathrm{~m} \mathrm{~s}^{-1}$ ) of a balloonborne upsondes provides much finer details of the vertical structure of landfalling hurricanes and their environment than the $11-21 \mathrm{~m} \mathrm{~s}^{-1}$ descent speeds of dropsondes. Given the need for observational data at a high temporal frequency and at small ranges from the hurricane center, a mobile sounding vehicle was used to obtain several vertical profiles throughout the course of the landfall of Hurricane Harvey.

After positioning it in Refugio ahead of the approaching eye, a radiosonde was launched at 0716 UTC 26 August in the inner-eyewall boundary to the calm eye center (Fig. 11). The balloon rose with an average velocity of approximately $2 \mathrm{~m} \mathrm{~s}^{-1}$ and proceeded to follow the inner-eyewall boundary when it traversed the entire circumference of the eye, passing directly over the launch point roughly $50 \mathrm{~min}$ later at an altitude of roughly $7.5 \mathrm{~km}$. Due to the structure of the winds around the hurricane circulation, the hodograph was plotted as a nearly complete circle, making 1.25 revolutions around the eyewall before the balloon burst at an altitude of $9.6 \mathrm{~km}$ and a pressure of $307 \mathrm{mb}$. The 
observed hodograph led to storm relative helicity (SRH) values of $-1,847 \mathrm{~m}^{2} \mathrm{~s}^{-2}$ in the $0-3-\mathrm{km}$ layer and $-758 \mathrm{~m}^{2} \mathrm{~s}^{-2}$ in the $0-1-\mathrm{km}$ layer, while the thermodynamic profile showed saturated conditions for the entire flight. For context, values of $300-400 \mathrm{~m}^{2} \mathrm{~s}^{-2}$ for $0-3-\mathrm{km}$ SRH represent typically significant severe weather days in the central plains of the United States.

Precipitable water is defined as a measure of the depth of liquid water at the surface that would result if all water vapor were precipitated out in a column. As a more practical use, the value is used to gauge the moisture content of the atmosphere and assess a flooding risk. With the saturated conditions and low surface pressure, the precipitable water content was measured at $8.28 \mathrm{~cm}$ for the Hurricane Harvey sounding at 0716 UTC. To place this value into context, it is likely the highest precipitable water value observed from a standard radiosonde flight without data errors in the continental United States (CONUS) according to the sounding climatology archive maintained by the Storm Prediction Center (Rogers et al. 2014). Strictly speaking, there are several soundings in the archive with values higher than $8.28 \mathrm{~cm}$, but these soundings are either incomplete or contain obvious errors, which led to artificially inflated precipitable water values. The climatology of soundings can be used to delineate a risk of heavy rain, and observed values above the 75 th percentile are an indication of a strong possibility of very heavy rain. Generally, values above $5.08 \mathrm{~cm}$ suggest excessive rainfall and that flooding may be a concern (J. Kurtz, NWS Senior Forecaster, 2018, personal communication).

This sounding, and others obtained for Hurricane Harvey, demonstrate the extreme environment present in landfalling tropical systems. Furthermore, rapid changes in this environment occur when approaching the center of circulation. More observations of this environment and the changes it undergoes as the system transitions to extratropical are needed to fully understand the landfalling process and the associated risks it presents.

CONCLUSIONS. Extreme winds with gusts over $60 \mathrm{~m} \mathrm{~s}^{-1}$ were found along the inner edge of the eyewall of Hurricane Harvey during landfall. Based on dualDoppler wind retrievals from a SMART radar and the NWS WSR-88D in Corpus Christi. These winds appear to be associated with the passage of a mesovortex observed along the inner edge of the eyewall of Harvey. A DOW radar that operated within the eye of Harvey as it passed over land documented the finer-scale structure of later mesovortices, finding that individual mesovortices had diameters of $5-8 \mathrm{~km}$ with embedded tornado-scale vortices on the order of $1 \mathrm{~km}$ in diameter (Wurman and Kosiba 2018). Analysis of the time series of wind records from in situ tower instruments indicated that the 3-s gust factor associated with the observed presence of mesovortices reached a value of 1.7, which is considerably higher than the 1.46-1.49 gust factor derived from theoretical turbulence models for a ten-minute record in these terrain conditions.

While extreme winds have been observed in mesovortices along the inner eyewall of other hurricanes, this study is one of the first to present a wind record and gust analysis along with dual-Doppler wind retrievals and detailed radar analysis from ground-based observing systems during landfall of a major hurricane. Additionally, a sounding taken in the eye of Harvey yielded an unprecedented amount of precipitable water for atmospheric soundings over the continental United States. Integrated observations of such detail are rather rare within the environment of landfalling hurricanes, yet such observations are important to documenting the internal structure of hurricanes and improving plans to mitigate their impact. Moreover, such datasets can be used to validate numerical simulations of hurricane structure at landfall, which would contribute to greater forecast accuracy of extreme impacts at shorter time and space scales.

While flooding from storm surge remains one of the greatest risk factors during hurricane landfall (Rappaport 2014), inland flooding caused by rainbands, the inner-core precipitation, and the eyewall can also lead to a significant number of fatalities in the United States (Rappaport 2000). As the coastal and nearby regions continue to grow in population (Crossett et al. 2004), it will be more difficult to conduct large-area evacuations. While current evacuations are based on storm surge forecasts, as future quantitative surface wind and precipitation forecasts become more accurate, that information may also assist emergency managers in developing targeted evacuation guidance. Even if a coastal location is not expected to be inundated by surge, the analysis provided here indicates that there remains the threat of extreme winds from mesovortices along the inner edge of the eyewall. It is important to recognize that observation and characterization of the finescale structures within landfalling tropical cyclones are required to achieve an enhanced level of situational awareness.

A major challenge to collecting integrated observations like those documented here is the need to support programs that collect data during the event. In particular, non-federal agency observing platforms have few avenues for obtaining support for such deployments. The variability in the number of 
landfalling major hurricanes, which may be zero for several consecutive years, gives appropriate pause to reviewers of proposals submitted through the normal grants process. Programs like Rapid Response Research (RAPID), sponsored by the National Science Foundation, tend to focus on collecting data after a disaster instead of during. For instance, the SMART radar team was awarded a RAPID proposal to reimburse their Harvey deployment a few weeks after collecting data during the landfall of Irma.

Given the short lead times of targets of opportunity, even the special agency programs that are established to fund urgent data collection currently cannot provide timely input for go-no-go deployment decisions in which significant financial resources must be obligated. Consequently, the collection of specialized high-temporal- and highspatial-resolution observations needed to further our physical understanding, validate simulated physical processes in numerical models, and improve forecasts and warnings of catastrophic events is severely limited. A paradigm shift in the ability of federal agencies to support high-impact, but infrequent, near-zero lead-time data collection is required if progress is to be made in addressing the many research questions and their applications described above. Both research and operational agencies should strive to develop appropriate mechanisms to support these operations.

ACKNOWLEDGMENTS. The authors wish to thank the National Science Foundation (CMMI-1055744 and AGS-1759479) and the National Severe Storms Laboratory for supporting field research.

We are also extremely grateful to the students, staff, and volunteers that made this field research possible. In no particular order, they are, for UF, Jon Sinnreich, Shelby Brothers, Samuel Collins, Brandon Czartzasty, Eric Johnson, Patrick McGovern, John Minor, and Daniel Prestridge, and for TTU, James Duncan, Jeff Livingston, John Geesling, and Lee Wilks.

\section{APPENDIX: NEAR-SURFACE MEASUREMENTS AND METADATA FROM FIXED AND}

ADAPTIVE MESONETS. Metadata (latitude and longitude, measurement height, etc.) for each adaptive and fixed observational station are shown in Tables A1-A7.

\begin{tabular}{|c|c|c|c|c|c|c|c|c|}
\hline Mesonet & $\begin{array}{c}\text { Station } \\
\text { name }\end{array}$ & $\begin{array}{l}\text { Station } \\
\text { ID }\end{array}$ & Landmark & Lat $\left({ }^{\circ}\right)$ & Lon $\left({ }^{\circ}\right)$ & $\begin{array}{l}\text { Height } \\
\text { (m) }\end{array}$ & $\begin{array}{c}\text { Averaging } \\
\text { period (min) }\end{array}$ & $\begin{array}{c}\text { Gust } \\
\text { duration (s) }\end{array}$ \\
\hline FCMP/towers & FCMP T2 & FCMP T2 & Rockport & 28.08880 & -97.05120 & 15 & 1 & 3 \\
\hline FCMP/towers & FCMP T3 & FCMP T3 & Port Lavaca & 28.61190 & -96.62520 & 15 & 1 & 3 \\
\hline TTU/StickNet & TT0I02A & TT0102A & Portland & 27.87936 & -97.29433 & 2 & 1 & 3 \\
\hline TTU/StickNet & TT0I03A & TT0I03A & Aransas Pass & 27.90926 & -97.13204 & 2 & 1 & 3 \\
\hline TTU/StickNet & TT0104A & TT0I04A & Rockport & 28.11096 & -97.02672 & 2 & $I$ & 3 \\
\hline TTU/StickNet & TT0I05A & TT0105A & Austwell & 28.33900 & -96.92954 & 2 & $\mathrm{I}$ & 3 \\
\hline TTU/StickNet & TT0I06A & TT0106A & Seadrift & 28.43935 & -96.72760 & 2 & 1 & 3 \\
\hline TTU/StickNet & TT0I08A & TT0I08A & Trade winds & 28.03384 & -97.23983 & 2 & 1 & 3 \\
\hline TTU/StickNet & TTOIIOA & TTOIIOA & Austwell & 28.40905 & -96.86999 & 2 & 1 & 3 \\
\hline TTU/StickNet & TTOIIIA & TTOIIIA & Port Alto & 28.66249 & -96.41518 & 2 & 1 & 3 \\
\hline TTU/StickNet & TTOII2A & TTOII2A & Port Lavaca & 28.58847 & -96.62765 & 2 & 1 & 3 \\
\hline TTU/StickNet & TT02I3A & TT02I3A & Corpus Christi & 27.70409 & -97.15087 & 2 & 1 & 3 \\
\hline TTU/StickNet & TT0214A & TT02I4A & Corpus Christi & 27.58605 & -97.21806 & 2 & 1 & 3 \\
\hline TTU/StickNet & TT0220A & TT0220A & Woodsboro & 28.16117 & -97.20979 & 2 & 1 & 3 \\
\hline CSWR/DOW & DOW8 Ano & DOW8 & Rockport & 28.08688 & -97.04672 & 8 & 1 & 3 \\
\hline CSWR/pod & PodB & PodB & Rockport & 28.08365 & -97.04365 & $I$ & $I$ & 3 \\
\hline CSWR/pod & PodC & PodC & Rockport & 28.08893 & -97.04319 & 1 & 1 & 3 \\
\hline CSWR/pod & PodD & PodD & Rockport & 28.11070 & -97.02666 & $I$ & 1 & 3 \\
\hline NSSL & $\begin{array}{l}\text { Mobile } \\
\text { mesonet }\end{array}$ & Probe I & Woodsboro & 28.04400 & -97.33210 & 3 & 1 & 3 \\
\hline NSSL & $\begin{array}{l}\text { Mobile } \\
\text { mesonet }\end{array}$ & Probe I & Woodsboro & 28.22420 & -97.34530 & 3 & 1 & 3 \\
\hline
\end{tabular}




\begin{tabular}{|c|c|c|c|c|c|c|c|}
\hline Mesonet & Station ID & $\begin{array}{l}\text { Height } \\
(\mathrm{m})\end{array}$ & $\begin{array}{l}\text { Max wind } \\
\left(\mathrm{m} \mathrm{s}^{-1}\right)\end{array}$ & $\begin{array}{c}\text { Averaging } \\
\text { period (min) }\end{array}$ & $\begin{array}{c}\text { Max gust } \\
\left(\mathrm{m} \mathrm{s}^{-1}\right)\end{array}$ & $\begin{array}{c}\text { Gust } \\
\text { duration (s) }\end{array}$ & $\begin{array}{c}\text { Captured } \\
\text { peak }\end{array}$ \\
\hline FCMP/towers & FCMP T2 & 15 & 49 & 1 & $63\left(65^{*}\right)$ & 3 & Yes \\
\hline FCMP/towers & FCMP T3 & 15 & 23 & 1 & 30 & 3 & Yes \\
\hline TTU/StickNet & TTOI02A & 2 & 26 & 1 & 34 & 3 & Yes \\
\hline TTU/StickNet & TT0I03A & 2 & 36 & 1 & 48 & 3 & Yes \\
\hline TTU/StickNet & TT0104A & 2 & 35 & 1 & 45 & 3 & No \\
\hline TTU/StickNet & TT0I05A & 2 & 37 & 1 & 46 & 3 & Yes \\
\hline TTU/StickNet & TT0106A & 2 & 29 & 1 & 39 & 3 & Yes \\
\hline TTU/StickNet & TT0108A & 2 & 37 & 1 & 44 & 3 & Yes \\
\hline TTU/StickNet & TTOIIOA & 2 & 35 & 1 & 46 & 3 & Yes \\
\hline TTU/StickNet & TTOIIIA & 2 & 21 & 1 & 27 & 3 & Yes \\
\hline TTU/StickNet & TTOII2A & 2 & 23 & 1 & 30 & 3 & Yes \\
\hline TTU/StickNet & TT02I3A & 2 & 34 & 1 & 41 & 3 & Yes \\
\hline TTU/StickNet & TT0214A & 2 & 27 & 1 & 35 & 3 & Yes \\
\hline TTU/StickNet & TT0220A & 2 & 38 & 1 & 44 & 3 & No \\
\hline CSWR/DOW & DOW8 & 8 & 46 & 1 & 60 & 3 & Yes \\
\hline CSWR/pod & PodB & 1 & 25 & 1 & 35 & 3 & No \\
\hline CSWR/pod & PodC & $\mathrm{I}$ & 25 & $\mathrm{I}$ & 34 & 3 & No \\
\hline CSWR/pod & PodD & 1 & 33 & 1 & 44 & 3 & No \\
\hline NSSL & Probe I & 3 & 34 & 1 & 42 & 3 & Yes \\
\hline NSSL & Probe I & 3 & 31 & 1 & 39 & 3 & Yes \\
\hline
\end{tabular}

* Based on a moving average of I Hz collected by an R. M. Young monitor.

\begin{tabular}{|c|c|c|c|c|c|c|c|}
\hline Mesonet & Station name & Station ID & Lat $\left({ }^{\circ}\right)$ & Lon $\left({ }^{\circ}\right)$ & $\begin{array}{l}\text { Height } \\
\text { (m) }\end{array}$ & $\begin{array}{l}\text { Averaging } \\
\text { period (min) }\end{array}$ & $\begin{array}{c}\text { Gust } \\
\text { duration (s) }\end{array}$ \\
\hline Earth Networks & Dow Chemical & SDRFT & 28.52487 & -96.77377 & 11 & 2 & 2 \\
\hline Earth Networks & $\begin{array}{c}\text { First Community } \\
\text { Bank }\end{array}$ & CCFCB & 27.79630 & -97.39213 & 65 & 2 & 2 \\
\hline Earth Networks & KRIS TV & KRIST & 27.79237 & -97.40117 & 11 & 2 & 2 \\
\hline Earth Networks & $\begin{array}{c}\text { Matagorda Bay } \\
\text { Pilots }\end{array}$ & MGBPS & 28.43806 & -96.41583 & 12 & 2 & 2 \\
\hline Earth Networks & Mike Shaw Kia & CRPMS & 27.69750 & -97.34777 & 9 & 2 & 2 \\
\hline Earth Networks & $\begin{array}{l}\text { Texas Maritime } \\
\text { Museum }\end{array}$ & RCKPR & 28.02669 & -97.04947 & 8 & 2 & 2 \\
\hline TAMU/TCOON & Aransas Pass Tower & 143701 & 27.83700 & -97.03900 & 14 & 2 & 5 \\
\hline TAMU/TCOON & $\begin{array}{c}\text { Aransas Wildlife } \\
\text { Refuge }\end{array}$ & AWRT2 & 28.22773 & -96.79658 & 12 & 2 & 5 \\
\hline TAMU/TCOON & Copano Bay & CPNT2 & 28.11444 & -97.02439 & 9 & 2 & 5 \\
\hline TAMU/TCOON & Lavaca Bay & VCAT2 & 28.64051 & -96.60976 & 6 & 2 & 5 \\
\hline TAMU/TCOON & Nueces Bay & NUET2 & 27.83218 & -97.48506 & 6 & 2 & 5 \\
\hline TAMU/TCOON & Packery Channel & РACT2 & 27.63457 & -97.23696 & II & 2 & 5 \\
\hline TAMU/TCOON & Port Aransas & RTAT2 & 27.83975 & -97.07270 & II & 2 & 5 \\
\hline TAMU/TCOON & Port O'Connor & PCNT2 & 28.44581 & -96.39551 & 9 & 2 & 5 \\
\hline TAMU/TCOON & Seadrift Harbor & SDRT2 & 28.40730 & -96.71220 & 10 & 2 & 5 \\
\hline WeatherFlow & Corpus Christi & XCRP & 27.59903 & -97.30449 & 10 & 1 & 3 \\
\hline WeatherFlow & Laguna Shores & XLAG & 27.63716 & -97.28678 & 10 & 1 & 3 \\
\hline WeatherFlow & Matagorda Bay & XMGB & 28.59107 & -95.98264 & 6 & 1 & 3 \\
\hline WeatherFlow & Wildcat & XWLD & 27.86703 & -97.32257 & 5 & 5 & 3 \\
\hline
\end{tabular}




\begin{tabular}{|c|c|c|c|c|c|c|c|}
\hline Mesonet & Station ID & $\begin{array}{l}\text { Height } \\
\text { (m) }\end{array}$ & $\begin{array}{l}\text { Max wind } \\
\left(\mathrm{m} \mathrm{s}^{-1}\right)\end{array}$ & $\begin{array}{l}\text { Averaging } \\
\text { period } \\
\text { (min) }\end{array}$ & $\begin{array}{c}\text { Max gust } \\
\left(\mathrm{m} \mathrm{s}^{-1}\right)\end{array}$ & $\begin{array}{c}\text { Gust } \\
\text { duration } \\
\text { (s) }\end{array}$ & $\begin{array}{c}\text { Captured } \\
\text { peak }\end{array}$ \\
\hline Earth Networks & SDRFT & II & 24 & 2 & 40 & 2 & No \\
\hline Earth Networks & CCFCB & 65 & 30 & 2 & 45 & 2 & Yes \\
\hline Earth Networks & KRIST & II & 17 & 2 & 32 & 2 & Yes \\
\hline Earth Networks & MGBPS & 12 & 14 & 2 & 21 & 2 & No \\
\hline Earth Networks & CRPMS & 9 & 15 & 2 & 24 & 2 & No \\
\hline Earth Networks & RCKPR & 8 & 21 & 2 & 34 & 2 & No \\
\hline TAMU/TCOON & I4370I & 14 & 47 & 2 & 56 & 5 & Yes \\
\hline TAMU/TCOON & AWRT2 & 12 & 35 & 2 & 47 & 5 & Yes \\
\hline TAMU/TCOON & CPNT2 & 9 & 37 & 2 & 49 & 5 & Yes \\
\hline TAMU/TCOON & VCAT2 & 6 & 27 & 2 & 34 & 5 & Yes \\
\hline TAMU/TCOON & NUET2 & 6 & 26 & 2 & 33 & 5 & Yes \\
\hline TAMU/TCOON & РАCT2 & II & 29 & 2 & 37 & 5 & Yes \\
\hline TAMU/TCOON & RTAT2 & II & 26 & 2 & 35 & 5 & Yes \\
\hline TAMU/TCOON & PCNT2 & 9 & 27 & 2 & 35 & 5 & Yes \\
\hline TAMU/TCOON & SDRT2 & 10 & 27 & 2 & 37 & 5 & Yes \\
\hline WeatherFlow & XCRP & 10 & 24 & $\mathrm{I}$ & 34 & 3 & Yes \\
\hline WeatherFlow & XLAG & 10 & 27 & $\mathrm{I}$ & 36 & 3 & Yes \\
\hline WeatherFlow & XMGB & 6 & 25 & 1 & 29 & 3 & Yes \\
\hline WeatherFlow & XWLD & 5 & 25 & 5 & 33 & 3 & No \\
\hline
\end{tabular}

\begin{tabular}{|c|c|c|c|c|c|c|c|}
\hline Network & Station name & Station ID & Lat $\left({ }^{\circ}\right)$ & Lon $\left({ }^{\circ}\right)$ & $\begin{array}{l}\text { Height } \\
\text { (m) }\end{array}$ & $\begin{array}{l}\text { Averaging } \\
\text { period } \\
\text { (min) }\end{array}$ & $\begin{array}{c}\text { Gust } \\
\text { duration } \\
\text { (s) }\end{array}$ \\
\hline FAA/AWOS & $\begin{array}{c}\text { Corpus Christi } \\
\text { NAS }\end{array}$ & KNGP & 27.68790 & -97.29160 & 10 & - & - \\
\hline FAA/AWOS & Mustang Beach & KRAS & 27.80830 & -97.08530 & 10 & - & - \\
\hline FAA/AWOS & Port Lavaca & KPKV & 28.64990 & -96.67990 & 10 & - & - \\
\hline NDBC/C-MAN & Port Aransas Pier & PTAT2 & 27.82591 & -97.05064 & 15 & 2 & 3 \\
\hline NOS/OOPS & Bob Hall Pier & MQTT2 & 27.58102 & -97.21650 & 12 & 2 & 5 \\
\hline NOS/OOPS & $\begin{array}{c}\text { Matagorda Bay } \\
\text { Entrance }\end{array}$ & 138488 & 28.42200 & -96.32700 & 12 & 2 & 5 \\
\hline NOS/OOPS & Rockport & RCPT2 & 28.01980 & -97.04810 & 7 & 2 & 5 \\
\hline NOS/OOPS & $\begin{array}{c}\text { South Bird Island- } \\
\text { NPS }\end{array}$ & IRDT2 & 27.48470 & -97.31810 & 11 & 2 & 5 \\
\hline NOS/NERRS & $\begin{array}{c}\text { Aransas Pass } \\
\text { Channel }\end{array}$ & MIST2 & 27.83810 & -97.05030 & 9 & 15 & - \\
\hline NOS/NERRS & Copano East & MAXT2 & 28.13235 & -97.03444 & 6 & 15 & 5 \\
\hline NWS/ASOS & Aransas Airport & KRKP & 28.08370 & -97.04670 & 10 & 2 & 3 \\
\hline NWS/ASOS & Corpus Christi Intl & KCRP & 27.77340 & -97.51300 & 10 & 2 & 3 \\
\hline USFS/RAWS & Aransas NWR & AFWT2 & 28.30444 & -96.82333 & 6 & 10 & 5 \\
\hline USFS/RAWS & Matagorda Island & MIRT2 & 28.12278 & -96.80222 & 6 & 10 & 5 \\
\hline
\end{tabular}




\begin{tabular}{|lccccccc|}
\hline TABLE A6. Maximum wind speed data from the state and federal stations during Hurricane Harvey. \\
\hline Network & Station ID & $\begin{array}{c}\text { Height } \\
(\mathbf{m})\end{array}$ & $\begin{array}{c}\text { Max } \mathbf{w i n d} \\
\left(\mathbf{m ~ s}^{-1}\right)\end{array}$ & $\begin{array}{c}\text { Averaging } \\
\text { period } \mathbf{( m i n})\end{array}$ & $\begin{array}{c}\text { Max gust } \\
\left(\mathbf{m} \mathbf{~ s}^{-1}\right)\end{array}$ & $\begin{array}{c}\text { Gust } \\
\text { duration } \mathbf{( s )}\end{array}$ & $\begin{array}{c}\text { Captured } \\
\text { peak }\end{array}$ \\
\hline FAA/AWOS & KNGP & 10 & 28 & - & 33 & - & No \\
\hline FAA/AWOS & KRAS & 10 & 24 & - & 30 & - & No \\
\hline FAA/AWOS & KPKV & 10 & 17 & - & 22 & - & No \\
\hline NDBC/C-MAN & PTAT2 & 15 & 43 & 2 & 56 & 3 & Yes \\
\hline NOS/OOPS & MQTT2 & 12 & 25 & 2 & 33 & 5 & Yes \\
\hline NOS/OOPS & I38488 & 12 & 28 & 2 & 34 & 5 & Yes \\
\hline NOS/OOPS & RCPT2 & 7 & 30 & 2 & 48 & 5 & No \\
\hline NOS/OOPS & IRDT2 & 11 & 24 & 2 & 32 & 5 & Yes \\
\hline NOS/NERRS & MIST2 & 9 & 43 & 15 & 0 & - & No \\
\hline NOS/NERRS & MAXT2 & 6 & 37 & 15 & 52 & 5 & No \\
\hline NWS/ASOS & KRKP & 10 & 23 & 2 & 31 & 3 & No \\
\hline NWS/ASOS & KCRP & 10 & 22 & 2 & 28 & 3 & No \\
\hline USFS/RAWS & AFWT2 & 6 & 23 & 10 & 48 & 5 & Yes \\
\hline USFS/RAWS & MIRT2 & 6 & 23 & 10 & 37 & 5 & No \\
\hline
\end{tabular}

\begin{tabular}{|c|c|c|c|c|c|c|}
\hline Station name & $\begin{array}{l}\text { Station name and } \\
\text { measurement }\end{array}$ & Lat $\left({ }^{\circ}\right)$ & Lon $\left({ }^{\circ}\right)$ & Level & $\begin{array}{l}\text { Wind speed } \\
\left(\mathrm{m} \mathrm{s}^{-1}\right)\end{array}$ & $\begin{array}{l}\text { Averaging } \\
\text { period (s) }\end{array}$ \\
\hline Mission 19/Ob 17 & KNHC: Dropsonde & 27.65000 & -96.53000 & WLI50 & 61 & - \\
\hline Mission 19/Ob 35 & KNHC: Dropsonde & 27.90000 & -96.75000 & WLI50 & 58 & - \\
\hline Mission 20/Ob 04 & KNHC: Dropsonde & 28.02000 & -96.90000 & WLI50 & 62 & - \\
\hline Mission 20/Ob 06 & KNHC: Dropsonde & 27.80000 & -96.90000 & WLI50 & 52 & - \\
\hline Mission 20/Ob I5 & KNHC: Dropsonde & 27.96000 & -96.94000 & WLI50 & 57 & - \\
\hline Mission 19/Ob 29 & KNHC: SFMR & 27.66700 & -96.71700 & Surface & 58 & 10 \\
\hline Mission 19/Ob 42 & KNHC: SFMR & 27.86700 & -96.56700 & Surface & 54 & 10 \\
\hline Mission 20/Ob 13 & KNHC: SFMR & 28.05000 & -96.71700 & Surface & 55 & 10 \\
\hline Mission 20/Ob 14 & KNHC: SFMR & 27.76700 & -96.91700 & Surface & 54 & 10 \\
\hline Mission 20/Ob 18 & KNHC: SFMR & 27.83300 & -96.96700 & Surface & 55 & 10 \\
\hline Mission 20/Ob 18 & KNHC: SFMR & 27.93300 & -97.05000 & Surface & 53 & 10 \\
\hline Mission 20/Ob 19 & KNHC: SFMR & 28.08300 & -96.73300 & Surface & 56 & 10 \\
\hline Mission 20/Ob 25 & KNHC: SFMR & 28.15000 & -96.71700 & Surface & 55 & 10 \\
\hline
\end{tabular}

\section{REFERENCES}

Abdullah, A. J., 1966: The spiral bands of a hurricane: A possible dynamic explanation. J. Atmos. Sci., 23, 367-375, https://doi.org/10.1175/1520 -0469(1966)023<0367:TSBOAH>2.0.CO;2.

Aberson, S. D., M. T. Montgomery, M. M. Bell, and M. Black, 2006: Hurricane Isabel (2003): New insights into the physics of intense storms. Part II: Extreme localized wind. Bull. Amer. Meteor. Soc., 87, 1349-1354, https://doi.org/10.1175/BAMS-87-10 -1349 .
_- J. A. Zhang, K. Nuñez Ocasio, S. D. Aberson, J. A. Zhang, and K. N. Ocasio, 2017: An extreme event in the eyewall of Hurricane Felix on 2 September 2007. Mon. Wea. Rev., 145, 2083-2092, https://doi .org/10.1175/MWR-D-16-0364.1.

Alford, A. A., and M. I. Biggerstaff, 2015: High-resolution dual-Doppler observations of tropical cyclone vortex Rossby waves. 37th Int. Conf. on Radar Meteorology, Amer. Meteor. Soc., 154, https://ams.confex.com /ams/37RADAR/webprogram/Paper275848.html.

$\longrightarrow$, and — 2017: Mobile radar observations of the kinematics and microphysics of Hurricanes Isaac 
(2012) and Hermine (2016). 38th Int. Conf. on Radar Meteorology, Amer. Meteor. 12B.3, Soc., https://ams .confex.com/ams/38RADAR/meetingapp.cgi /Paper/320753.

,-- , and D. P. Betten, 2016: Mobile radar observation of vortex Rossby waves in three landfalling tropical cyclones. 32nd Conf. on Hurricanes and Tropical Meteorology, Amer. Meteor. Soc., 13B.4, https://ams.confex.com/ams/32Hurr/webprogram /Paper293013.html.

Baker, A. K., M. D. Parker, and M. D. Eastin, 2009: Environmental ingredients for supercells and tornadoes within Hurricane Ivan. Wea. Forecasting, 24, 223-224, https://doi.org/10.1175/2008WAF2222146.1.

Balderrama, J. A., and Coauthors, 2011: The Florida Coastal Monitoring Program (FCMP): A review. J. Wind Eng. Ind. Aerodyn., 99, 979-995, https://doi .org/10.1016/j.jweia.2011.07.002.

Biggerstaff, M. I., and Coauthors, 2005: The Shared Mobile Atmospheric Research and Teaching (SMART) radar: A collaboration to enhance research and teaching. Bull. Amer. Meteor. Soc., 86, 1263-1274, https://doi.org/10.1175/BAMS-86-9-1263.

— Z Z. Zounes, A. A. Addison, G. D. Carrie, J. T. Pilkey, M. A. Uman, and D. M. Jordan, 2017: Flash propagation and inferred charge structure relative to radarobserved ice alignment signatures in a small Florida mesoscale convective system. Geophys. Res. Lett., 44, 8027-8036, https://doi.org/10.1002/2017GL074610.

Black, P. G., and F. D. Marks, 1991: The structure of an eyewall mesovortex in Hurricane Hugo. Proc. 19th Conf. on Hurricanes and Tropical Meteorology, Miami, FL, Amer. Meteor. Soc., 579-582.

— S. J. Buchan, and R. L. Cohen, 1999: The tropical cyclone eyewall mesovortex: A physical mechanism explaining extreme peak gust occurrence in TC Olivia, 4 April 1996 on Barrow Island, Australia. Proc. 31st Offshore Technology Conf., Houston, TX, Offshore Technology Conference, 10792, https://doi .org/10.4043/10792-MS.

Blake, E. S., and D. A. Zelinsky, 2018: National Hurricane Center tropical cyclone report: Hurricane Harvey. NOAA/NWS Rep., 77 pp., www.nhc.noaa .gov/data/tcr/AL092017_Harvey.pdf.

Braun, S. A., 2002: A cloud-resolving simulation of Hurricane Bob (1991): Storm structure and eyewall buoyancy. Mon. Wea. Rev., 130, 1573-1592, https:// doi.org/10.1175/1520-0493(2002)130<1573:ACRSOH $>2.0 . \mathrm{CO} ; 2$.

Chen, Y., and M. K. Yau, 2001: Spiral bands in a simulated hurricane. Part I: Vortex Rossby wave verification. J. Atmos. Sci., 58, 2128-2145, https://doi.org/10.1175 /1520-0469(2001)058<2128:SBIASH>2.0.CO;2.
Corbosiero, K. L., J. Molinari, A. R. Aiyyer, and M. L. Black, 2006: The structure and evolution of Hurricane Elena (1985). Part II: Convective asymmetries and evidence for vortex Rossby waves. Mon. Wea. Rev., 134, 3073-3091, https://doi.org/10.1175 /MWR3250.1.

Crossett, K., T. J. Culliton, P. Wiley, and T. R. Goodspeed, 2004: Population trends along the coastal United States, 1980-2008. National Oceanic and Atmospheric Administration Rep., 47 pp.

Curtis, L., 2004: Midlevel dry intrusions as a factor in tornado outbreaks associated with landfalling tropical cyclones from the Atlantic and Gulf of Mexico. Wea. Forecasting, 19, 411-427, https://doi.org/10.1175/1520 -0434(2004)019<0411:MDIAAF>2.0.CO;2.

Eastin, M. D., W. M. Gray, and P. G. Black, 2005: Buoyancy of convective vertical motions in the inner core of intense hurricanes. Part II: Case studies. Mon. Wea. Rev., 133, 209-227, https://doi.org/10.1175 /MWR-2849.1.

Fernández-Cabán, P. L., and F. J. Masters, 2017: Near surface wind longitudinal velocity positively skews with increasing aerodynamic roughness length. J. Wind Eng. Ind. Aerodyn., 169, 94-105, https://doi .org/10.1016/j.jweia.2017.06.007.

Franklin, J. L., S. J. Lord, and F. D. Marks Jr., 1988: Dropwindsonde and radar observations of the eye of Hurricane Gloria (1985). Mon. Wea. Rev., 116, 1237-1244, https://doi.org/10.1175/1520 -0493(1988)116<1237:DAROOT>2.0.CO;2.

Gao, C., and P. Zhu, 2016: Vortex Rossby wave propagation in baroclinic tropical cyclone-like vortices. Geophys. Res. Lett., 43, 578-589, https://doi .org/10.1002/2016GL071662.

Hirth, B. D., J. L. Schroeder, C. C. Weiss, D. A. Smith, and M. I. Biggerstaff, 2012: Research radar analysis of the internal boundary layer over Cape Canaveral, Florida, during the landfall of Hurricane Frances (2004). Wea. Forecasting, 27, 1349-1372, https://doi .org/10.1175/WAF-D-12-00014.1.

Ho, F. P., and J. F. Miller, 1982: Pertinent meteorological and hurricane tide data for Hurricane Carla. NOAA Tech. Rep. NWS 32, 119 pp.

Knupp, K. R., J. Walters, and M. Biggerstaff, 2006: Doppler profiler and radar observations of boundary layer variability during the landfall of Tropical Storm Gabrielle. J. Atmos. Sci., 63, 234-251, https:// doi.org/10.1175/JAS3608.1.

Kosiba, K., J. Wurman, F. J. Masters, P. Robinson, and C. Alexander, 2013: Mapping of near-surface winds in Hurricane Rita using fine-scale radar, anemometer, and land-use data. Mon. Wea. Rev., 141, 4337-4349, https://doi.org/10.1175/MWR-D-12-00350.1. 
Kwon, D.-K., and A. Kareem, 2009: Gust-front factor: New framework for wind load effects on structures. J. Struct. Eng., 135, 717-732, https://doi.org/10.1061 /(ASCE)0733-9445(2009)135:6(717).

Landsea, C. W., and J. L. Franklin, 2013: Atlantic hurricane database uncertainty and presentation of a new database format. Mon. Wea. Rev., 141, 3576-3592, https://doi.org/10.1175/MWR-D-12-00254.1.

Lorsolo, S., J. L. Schroeder, P. Dodge, and F. Marks Jr., 2008: An observational study of hurricane boundary layer small-scale coherent structures. Mon. Wea. Rev., 136, 2871-2893, https://doi.org /10.1175/2008MWR2273.1.

Marks, F. D., Jr., P. G. Black, M. T. Montgomery, and R. W. Burpee, 2008: Structure of the eye and eyewall of Hurricane Hugo (1989). Mon. Wea. Rev., 136, 1237-1259, https://doi.org/10.1175/2007MWR2073.1.

Masters, F. J., P. J. Vickery, P. Bacon, and E. N. Rappaport, 2010: Toward objective, standardized intensity estimates from surface wind speed observations. Bull. Amer. Meteor. Soc., 91, 1665-1682, https://doi .org/10.1175/2010BAMS2942.1.

McCaul, E. W., Jr., 1991: Buoyancy and shear characteristics of hurricane-tornado environments. Mon. Wea. Rev., 119, 1954-1978, https://doi.org/10.1175/1520 -0493(1991)119<1954:BASCOH>2.0.CO;2.

Menelaou, K., and M. K. Yau, 2014: On the role of asymmetric convective bursts to the problem of hurricane intensification: Radiation of vortex Rossby waves and wave-mean flow interactions. J. Atmos. Sci., 71, 2057-2077, https://doi.org/10.1175/JAS-D-13-0343.1.

Montgomery, M. T., and R. J. Kallenbach, 1997: A theory for vortex Rossby-waves and its application to spiral bands and intensity changes in hurricanes. Quart. J. Roy. Meteor. Soc., 123, 435-465, https://doi .org/10.1002/qj.49712353810.

Morrison, I., S. Businger, F. Marks, P. Dodge, and J. A. Businger, 2005: An observational case for the prevalence of roll vortices in the hurricane boundary layer. J. Atmos. Sci., 62, 2662-2673, https://doi.org/10.1175 /JAS3508.1.

Persing, J., and M. T. Montgomery, 2003: Hurricane superintensity. J. Atmos. Sci., 60, 2349-2371, https://doi.org/10.1175/1520-0469(2003)060<2349: $\mathrm{HS}>2.0 . \mathrm{CO} ; 2$.
Pilkey, J., and Coauthors, 2013: Rocket-and-wire triggered lightning in 2012 Tropical Storm Debby in the absence of natural lightning. J. Geophys. Res. Atmos., 118, 13 158-13 174, https://doi.org/10.1002 /2013JD020501.

Rappaport, E. N., 2000: Loss of life in the United States associated with recent Atlantic tropical cyclones. Bull. Amer. Meteor. Soc., 81, 2065-2073, https://doi .org/10.1175/1520-0477(2000)081<2065:LOLITU $>2.3 . \mathrm{CO} ; 2$.

— 2014: Fatalities in the United States from Atlantic tropical cyclones: New data and interpretation. Bull. Amer. Meteor. Soc., 95, 341-346, https://doi .org/10.1175/BAMS-D-12-00074.1.

Rogers, J. W., R. L. Thompson, and P. T. Marsh, 2014: Potential applications of a CONUS sounding climatology developed at the Storm Prediction Center. 27th Conf. Severe Local Storms, Madison, WI Amer. Meteor. Soc., 145, https://ams.confex.com /ams/27SLS/webprogram/Paper255385.html.

Roueche, D. B., F. T. Lombardo, R. J. Krupar III, and D. J. Smith, 2018: Collection of perishable data on wind- and surge-induced residential building damage during Hurricane Harvey (TX). DesignSafe-CI, accessed 20 February 2019, https://doi.org/10.17603 /DS2DX22.

von Kármán, T., 1948: Progress in the statistical theory of turbulence. Proc. Natl. Acad. Sci. USA, 34, 530539, https://doi.org/10.1073/pnas.34.11.530.

Weiss, C. C., and J. L. Schroeder, 2008: StickNet: A new portable rapidly deployable surface observation system. Bull. Amer. Meteor. Soc., 89, 1502-1503.

Wingo, S. M., and K. R. Knupp, 2016: Kinematic structure of mesovortices in the eyewall of Hurricane Ike (2008) derived from ground-based dual-Doppler analyses. Mon. Wea. Rev., 144, 4245-4263, https:// doi.org/10.1175/MWR-D-16-0085.1.

Wurman, J., and J. Winslow, 1998: Intense sub-kilometer-scale boundary layer rolls observed in Hurricane Fran. Science, 280, 555-557, https://doi.org/10.1126 /science.280.5363.555.

— , and K. Kosiba, 2018: The role of small-scale vortices in enhancing surface winds and damage in Hurricane Harvey. Mon. Wea. Rev., 146, 713-722, https://doi.org/10.1175/MWR-D-17-0327.1. 
AMS titles now

available as eBooks

at springer.com

\section{AMS BOOKS}

\section{RESEARCH APPLICATIONS HISTORY}

www.ametsoc.org/amsbookstore

Springer

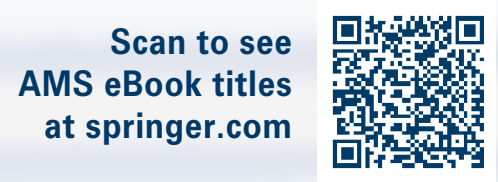

Springer

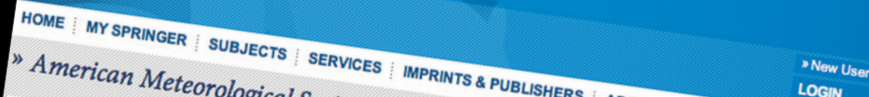

"American Meteorological SOCiety
"AOMTIN

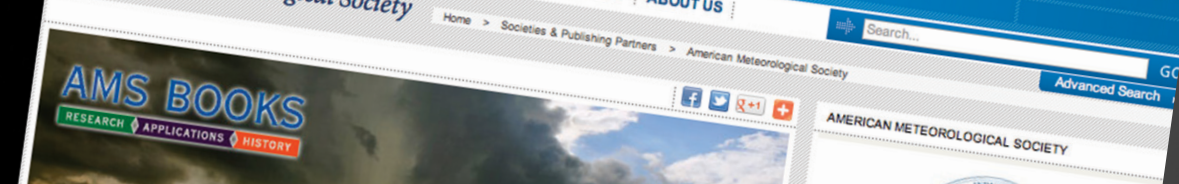

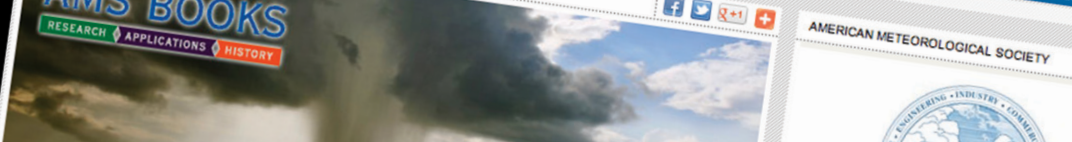

American Meteorol

Promoting the dewerogical Society

the atmos the deverap

the atmospheric and relont and disseminatb of

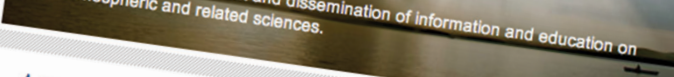

American Meteorological Society eB

AMS Books

published by the AMs a monograph publishing prent

shing program related to ho poer-

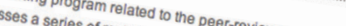

related to the as eBooks) as weil ar ariy out-ortprint vol metoorological and historica journals

to the atmospheric sciences a growing list of academis, which have been urough ographs

ind policy, and general-interest books

Sort listing by:

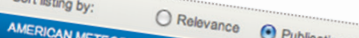

वध्ये Exporit to $\mathrm{CSO}$

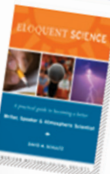

Eloquent Science

Bloquent Scie

A Practical Guite

Schulta, David
2009

Price from $\$ 45.00$

copyright Year

Avalobe

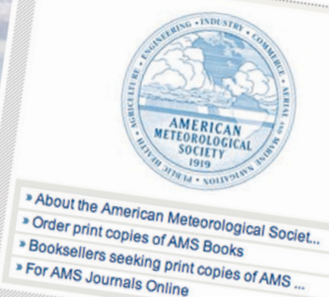

RESOURCES

Stay Informed

Receive notitication of now releases from
Books

Sub

AMS 